\title{
4. SCALY FABRICS IN SHEARED CLAYS FROM THE DÉCOLLEMENT ZONE OF THE BARBADOS ACCRETIONARY PRISM ${ }^{1}$
}

\author{
P. Labaume, ${ }^{2}$ A.J. Maltman, ${ }^{3}$ A. Bolton, ${ }^{3}$ D. Tessier,${ }^{4}$ Y. Ogawa,${ }^{5}$ and S. Takizawa ${ }^{5}$
}

\begin{abstract}
Scaly fabrics in the décollement at the toe of the northern Barbados accretionary prism occur in centimeter-thick zones interpreted as the horizons where tectonic displacement is concentrated. Detailed microstructural investigations of the scaly fabrics have been carried out, using optical, scanning (secondary and backscattered modes), and transmission electron microscopy. These observations show that the scaly fabrics essentially comprise three types of microstructures, which arise from a combination of shear and flattening. In these microstructures, strain is concentrated in micrometer- to millimeter-thick deformation bands, caused by clay-particle rotation associated with porosity collapse (compactional plastic strain), resulting in the formation of domains with marked preferred orientation of clay particles. However, this preferred orientation affects only a minor part of the sediment involved in the scaly-fabric zones and only a small proportion of the total décollement thickness. On the basis of the mode of microstructure associations, we propose a model for the kinematic evolution of the scaly-fabric zones. In these, deformation initiates by the formation of a spaced foliation corresponding to flattening band arrays, then continues by concentration of shear strain in S-C (schistosité-cisaillement [schistosity-shear]) bands geometrically analogous to the S-C tectonites common in metamorphic shear zones. Partitioning of deformation results in the late formation of fracture networks at the periphery of the S-C bands, the fractures networks being possible precursors of S-C band widening. Compactional strain in the deformation bands is typical of normally or undercompacted sediments and implies expulsion of pore fluid. Preferred orientation of clay particles makes the deformation bands potential pathways for fluid circulation in deformation zones, but compactional strain requires the bands to be dilated by excess pore pressure to have significant permeability. We infer cyclic variations of stress state in the scaly-fabric zones, related to pore-pressure variations. Formation of scaly fabrics by compactional plastic shear strain would be achieved under relatively low pore pressure and significant shear stress, whereas high pore pressure would inhibit further compactional strain while increasing permeability. Tectonic displacement is likely to be favored at the sharp boundaries of the scaly-fabric zones during high pore-pressure episodes; formation of the scaly fabrics thus would account for only part of the cumulative displacement.
\end{abstract}

\section{INTRODUCTION}

Mudstone-rich sequences in orogenic belts are commonly typified by "scaly fabrics," sets of surfaces that divide the sediment into millimeter- to centimeter-scale lenses. These fabrics are interpreted as the result of shear deformation, particularly in those tectonic units that have undergone long-distance lateral displacements in relatively superficial (no or very low-grade metamorphism) conditions and have developed a "mélange" texture (e.g., Cowan, 1985; Waldron et al., 1988; Agar et al., 1989; Lash, 1989; Byrne and Fisher, 1990; Labaume et al., 1991; Jeanbourquin, 1994). The nature and origin of scaly fabrics are thus important in understanding convergent plate margin settings, and, because the fabrics form connected surface networks and are commonly mineralized, they are important in understanding the relationships between clay shearing and fluid behavior in deformation zones. However, the study of scaly fabrics is made difficult by several factors: (1) material is difficult to sample in the field and to process for microstructural observations, because it is often fragile and affected by weathering; (2) the fabrics lack kinematic and diagenetic/metamorphic markers and may be overprinted by later deformation; and (3) existing descriptions of "scaly fabrics" involve

${ }^{1}$ Shipley, T.H., Ogawa, Y., Blum, P., and Bahr, J.M. (Eds.), 1997. Proc. ODP, Sci. Results, 156: College Station, TX (Ocean Drilling Program).

${ }^{2}$ Laboratoire de Géophysique Interne et Tectonophysique, CNRS-Université Joseph Fourier, BP 53X, 38041 Grenoble Cedex 9, France. pierre.labaume@ obs.ujf-grenoble.fr.

${ }^{3}$ Institute of Earth Studies, University of Wales, Aberystwyth, Wales, SY23 3DB, United Kingdom.

${ }^{4}$ Laboratoire de Science du Sol, Institut National de la Recherche Agronomique, 78026 Versailles, France.

${ }^{5}$ Institute of Geoscience, University of Tsukuba, Tsukuba, Ibaraki 305, Japan. a confusing variety of macro- and micro-structures, related to different original lithologies and deformation processes (Agar et al., 1989).

Some of these problems can be overcome by studying recently formed scaly fabrics that have remained where they were formed, such as the toe of active accretionary prisms. For this reason, deepsea drilling has provided much of the new information on scaly fabrics (Lundberg and Moore, 1986; Moore et al., 1986; Maltman et al., 1993).

Cores recovered at the toe of the Barbados accretionary prism during Deep Sea Drilling Project (DSDP) Leg 78A and Ocean Drilling Program (ODP) Leg 110 have made this prism a much-cited example of scaly fabrics formed in clay-rich lithologies (Cowan et al., 1984; Behrmann et al., 1988; Agar et al., 1989; Brown and Behrmann, 1990; Prior and Behrmann, 1990a, 1990b). During these legs, the scaly fabrics were successfully used as the main structural feature for defining fault zones in the prism and the décollement. Shore-based backscattered-mode scanning electron microscope (SEM) observations of samples from Hole 671B of Leg 110 showed that scaly fabrics along a thrust about $130 \mathrm{~m}$ below sea floor (mbsf) correspond to a strong preferred orientation of clay particles, but suggested that scaly fabrics in the basal décollement show no such alignment (Prior and Behrmann, 1990a, 1990b). In the latter case, Prior and Behrmann (1990a, 1990b) interpreted the scaly fabrics as core recovery-related features resulting from closely-spaced fracturing during unloading of stressed sediment. In conclusion, Prior and Behrmann (1990a, 1990 b) suggested that different types of scaly fabrics form in different parts of the prism, and they proposed that the absence of clayparticle preferred orientation in the décollement results from inhibition of pore collapse by high pore pressure.

In the present paper, we describe the scaly fabrics observed in cores recovered during ODP Leg 156 (Shipley, Ogawa, Blum, et al., 
1995), in the same area as that studied during DSDP Leg 78A and ODP Leg 110. Samples were collected from the décollement interval in Holes 948C, at the same position as Leg 110 Hole 671B, and 949B, located $900 \mathrm{~m}$ north-northeast of Leg 110 Hole 675A. These locations allow reliable comparison of Leg 156 samples with samples from previous legs. Excellent core recovery and an unusually long time available for shipboard core description allowed us to improve significantly the description of the macroscopic characters of the scaly fabrics and their structural distribution (Shipley, Ogawa, Blum, et al., 1995). The latter aspect is discussed further in Maltman et al. (Chapter 22, this volume). This paper focuses on the microstructural aspects of scaly fabrics, studied through optical, scanning, and transmission electron microscope observations. These observations do not support inferences of previous work (Prior and Behrmann, 1990a, $1990 b$ ). Our work clearly demonstrates that clay particles are preferentially oriented in the scaly fabrics from the décollement zone, giving new insights on the deformation mechanisms and kinematic evolution of the scaly fabrics at the particle scale.

\section{METHODS}

While on board, we differentiated as much as possible between the different types and varying intensities of scaly fabrics. We also paid close attention to their vertical distribution, that is, we did not define broad intervals dominated by scaly fabrics but tried to reach millimeter-scale resolution in analyzing the structural zonation (Shipley, Ogawa, Blum, et al., 1995). This allowed precise assessment of mesostructure distribution and the pertinent choice of samples for shore-based microstructural studies.

Special methods of sample processing were required for the shore-based studies because the cored sediments are poorly consolidated and their smectitic composition prevents using water. The samples chosen for making thin sections were slowly (2-3 weeks) air dried at room temperature, then impregnated under vacuum with low-viscosity epoxy resin. Either the resin or the samples were moderately heated $\left(\leq 60^{\circ} \mathrm{C}\right)$ before impregnation to facilitate resin penetration. Efforts to impregnate samples without drying by using interstitial water-acetone replacement were unsuccessful, because the samples disaggregated in the acetone bath. The thin sections were prepared using standard procedures, but the lubricant for the saws and hand-grinding was oil instead of water. Some of the thin sections were not covered to allow SEM observations. The samples cracked somewhat during air-drying. However, the cracks do not prevent recognition of the microstructural relationships within the samples, and we believe that drying did not significantly perturb the clay-particle arrangement observed under the microscope.

The thin sections were first observed under the optical microscope to determine the millimeter-scale structures and relate them to the macroscopic structures. The uncovered thin sections were then observed under the SEM, used in backscattered mode and coupled with an X-ray microanalysis system (energy dispersive spectrometer, EDS). This allowed both textural observations at the micrometric scale and qualitative assessment of the chemical-element content of the different mineral phases. In some cases, the SEM observations were made on the sawn surfaces of the blocks from which the thin sections were made. Before observation, the sawn surfaces were reimpregnated with a low-viscosity epoxy resin and polished using oil as a lubricant.

SEM observations were also made on the rough surfaces of small pieces taken either from the air-dried samples, or from samples prepared following a method developed at the University of Tsukuba. In this method, the sample is dipped into ethyl alcohol for about one month, then into tri-butyl alcohol for some months, and finally freeze-dried with liquid nitrogen. This method allows optimal preservation of microstructures in samples, including clay minerals. The samples were observed in secondary mode, giving a topographic im- age of the sample surface. This simple and standard technique proved to be effective for observation of clay-particle arrangement and assessment of pore geometry.

Complementary observations were made on millimeter-scale cuts using the transmission electron microscope (TEM). The cuts were prepared from samples impregnated without drying, following a method developed at the Institut National de la Recherche Agronomique, Versailles (Tessier, 1984; Hetzel et al., 1994). Small (a few cubic millimeters) pieces of wet sediment were cut with a knife, then immersed in dissolved agar gum. The latter prevents drying and deformation of the sample, but is permeable to the solvents and resin used for impregnation. After solidification of the agar, interstitial water-resin replacement was achieved by successively placing the samples in methanol, propylene oxide, and low-viscosity epoxy resin baths. After drying, the cuts were made with an ultramicrotome. Line drawings of the clay particles seen on TEM images, with folia oriented sub-perpendicular to the plane of observation, enabled qualitative assessment of the degree of clay-particle preferred orientation in and outside the scaly-fabric zones.

\section{MACROSCOPIC CHARACTER OF THE SCALY FABRICS}

\section{Cored Intervals}

In Holes 948C and 949B, cores were recovered from the lower part of the accretionary prism, the décollement, and the upper part of the underthrust section (Shipley, Ogawa, Blum, et al., 1995; Maltman et al., Chapter 22, this volume). In both holes, a major lithologic change occurs within the décollement zone. The lower part of the prism and upper part of the décollement are formed of Miocene hemipelagic claystones with a few intercalations of thin volcanic ash layers (lithologic Unit II), and the lower part of the décollement and the underthrust section are a late Oligocene very fine-grained turbidite succession with hemipelagic claystone intercalations (lithologic Unit III). Although the clay-rich sediments are generally firm enough to be referred to as "claystones," they are only partially lithified; all can be scratched with a nail, cut with a knife, and turned into mud when rubbed between fingers under water.

In lithologic Unit II claystones, the main minerals determined by shipboard X-ray diffraction analysis are clay (range of mean values: $60 \%-68 \%)$, quartz $(26 \%-31 \%)$, and feldspar $(5 \%-14 \%)$; calcite is generally absent or very low $(<1 \%)$, except in a few decameters-thick intervals where its mean abundance reaches up to $15 \%$. The most abundant clay mineral is smectite $(35 \%-50 \%)$, others are illite $(4 \%-$ $19 \%)$ and kaolinite $(4 \%-10 \%)$. The ranges of mean values of porosity are $54 \%-57 \%$ in Hole $948 \mathrm{C}$ and $55 \%-66 \%$ in Hole $949 \mathrm{~B}$, and that of bulk density is $1.8-1.9 \mathrm{~g} / \mathrm{cm}^{3}$.

In lithologic Unit III, the bulk mineralogy of claystone layers, where the scaly fabrics are developed, is similar to that of lithologic Unit II claystones. However, illite is the most abundant clay mineral in lithologic Unit III $(32 \%-37 \%)$. The mean values of porosity are $50 \%$ in Hole $948 \mathrm{C}$ and 52\% in Hole 949B, and those of bulk density are $2 \mathrm{~g} / \mathrm{cm}^{3}$ and $1.9 \mathrm{~g} / \mathrm{cm}^{3}$, respectively.

More details on the vertical variations of mineralogy, porosity, bulk density, and other physical properties of the sediments are in Shipley, Ogawa, Blum, et al. (1995). In the present study, we did not observe any influence of these variations on scaly fabric features. Their possible influence on other structural aspects is discussed in Maltman et al. (Chapter 22, this volume).

\section{Core-Scale Deformation Features}

Most deformation features seen in cores from both holes can be classified into three types, as explained in the shipboard report (Shipley, Ogawa, Blum, et al., 1995): 
1. Fracture networks correspond to sets of more or less closely (millimeter to centimeter) spaced fractures of variable orientation, some showing polished, and in some cases striated, surfaces. The fractures show cross-cutting relationships rather than anastomosing patterns. They form boundaries around lenses of macroscopically undeformed sediment. Fracture networks are typical of the weakly deformed intervals in lithologic Unit II (FN in Fig. 1A1). The absence of visible bedding makes it difficult to assess possible offsets across the fractures.

2. Stratal disruption refers to intervals where bedding is visible, but disrupted/rotated by extensional and/or contractional shear surfaces with a millimeter to centimeter spacing. Stratal disruption is typical of the weakly deformed intervals in lithologic Unit III (SD in Fig. 1A2).

3. Scaly fabrics are anastomosing, commonly polished, or in some cases striated, surfaces that divide the sediment into lenses. Surfaces in scaly fabrics are more closely spaced than those in the fracture networks, and the overall orientation defines a foliation within the deformed sediment (Fig. 1B, C). Depending on surface spacing, scaly fabrics can be qualified as weak/moderate (millimeter spacing) or intense (submillimeter spacing). Lenses of sediment bounded by the surfaces are macroscopically undeformed. The scaly fabrics affect exclusively clayey lithologies: lithologic Unit I and claystones in lithologic Unit II. They have a similar appearance in both units.

The scaly fabrics occur in millimeter- to centimeter-thick intervals referred to as "scaly-fabric zones" (SFZ in Fig. 1). The zone boundaries are sharp surfaces, separating sediment with scaly fabric inside the zone from the undeformed or weakly deformed sediment outside with fracture networks or stratal disruption (Fig. 1B, C). In most of the zones observed, the scaly fabric is intense, but millimetric lenses of macroscopically undeformed sediment bounded by the fabric are common. The overall foliation is oblique to sub-parallel to the zone boundaries and commonly rotated along subhorizontal drillinginduced rupture surfaces ("biscuit boundaries," thick arrows in Fig. 1A). Restoration of the original geometry, however, shows that the foliation originally dipped in a single direction across the whole zones.

In some cases, the scaly fabric zones are decorated by veins of carbonate ( \pm barite) or smectite-phillipsite (a zeolite). These veins occur parallel to the foliation, the zone boundaries, or internal shear surfaces (Labaume et al., Chapter 5, this volume). In one case, isolated prismatic barite crystals up to $0.5 \mathrm{~mm}$ long occur parallel to the fabric (Sample 156-948C-10X-5, 3-10 cm). The scaly-fabric zones may also show greenish to brownish alteration colors. In general, alteration colors do not extend into the undeformed sediment more than a few centimeters to decimeters away from the boundaries of the zones. In some cases, they end abruptly at these boundaries. The mineralized veins, isolated barite crystals, and alteration colors imply that the flow of diagenetic fluid was localized along the scaly-fabric zones (Maltman et al., Chapter 22, this volume).

\section{Distribution of the Scaly-Fabric Zones}

In both cored holes, the scaly-fabric zones show a similar macroscopic distribution. The zones occur in intervals a few meters to tens of meters thick, which were used to define fault zones in the prism and the décollement (Shipley, Ogawa, Blum, et al., 1995; Maltman et al., Chapter 22, this volume). In these fault zones, the scaly-fabric zones are interpreted as the horizons where shear deformation and tectonic displacement are concentrated. In most cases, and particularly in the décollement, the boundaries of the scaly-fabric zones are subhorizontal. However, some zones in the prism show inclined boundaries, and are interpreted as thrust faults.

The distribution of scaly-fabric zones within the faults attests to the highly heterogeneous distribution of shear deformation (Fig. 1A)
(Shipley, Ogawa, Blum, et al., 1995; Maltman et al., Chapter 22, this volume). The scaly-fabric zones rarely exceed $10 \mathrm{~cm}$ in thickness (the thickest zone observed is $33 \mathrm{~cm}$ thick; interval 156-949B-13X$1,67-100 \mathrm{~cm}$ ), and they occupy only a minor part of the total faultzone thickness. The intervals between the scaly-fabric zones correspond to more or less intensely developed fracture networks (in lithologic Unit II; Fig. 1A1) or stratal disruption (in lithologic Unit III; Fig. 1A2), and in some cases to macroscopically undeformed sediment. These characteristics are particularly well illustrated in the décollement cored in Hole 948C. The décollement is $38 \mathrm{~m}$ thick (from 491 to $529 \mathrm{mbsf}$ ) and shear deformation is distributed over a total of 98 scaly-fabric zones. The thickest zone is only $22 \mathrm{~cm}$ thick (interval 156-948C-11X-2, 128-150 cm) and the cumulative thickness of the zones is $3.3 \mathrm{~m}$, corresponding to only $8.8 \%$ of the total thickness of the décollement. Undeformed to poorly deformed intervals are up to several decimeters thick.

\section{MICROSCOPIC APPEARANCE OF THE SCALY FABRICS}

Microscopic observations show that the macroscopic scaly fabrics correspond to a combination of three types of elementary microstructural features in which strain is localized in $\mu \mathrm{m}$ - to mm-thick deformation bands. One of the microstructures is analogous to the fracture networks seen at the macroscopic scale. Of the other two microstructures, one corresponds closely to the $\mathrm{S}-\mathrm{C}$ (schistosité-cisaillement [schistosity-shear]) tectonites well known in metamorphic shear zones. Structures falling in this group are therefore referred to as S-C bands. The other microstructure is a spaced foliation (note that the latter term is used here in a general descriptive sense, and we infer no particular genetic analogy between the spaced foliation observed in our samples, and other types of spaced foliation described elsewhere, e.g., Lundberg and Moore, 1986). In this section, we first describe the clay-particle arrangement of claystones outside the deformation bands, and then the three microstructures and associated clay-particle arrangements that comprise scaly fabrics. In each case, we describe the microstructures as they are seen using the different microscopic techniques, which offer various degrees of magnification. Finally, we discuss the common way in which the three microstructures are associated in forming the scaly fabrics.

\section{Claystones Outside Deformation Bands}

\section{Optical Microscopy}

At this scale of observation, the clay particles are not visible, and the macroscopically undeformed claystone presents (1) a homogeneous, massive aspect in the case of lithologic Unit II, and (2) a massive aspect or a subtle layering in the case of lithologic Unit III.

\section{Electron Microscopy}

The most detailed images have been obtained with the secondary mode SEM and the TEM (Fig. 2). In lithologic Unit II, secondary mode SEM images show a highly porous arrangement of randomly oriented clay particles (Fig. 2A, B); pores are polygonal, up to 5- $\mu \mathrm{m}$ across. A similar arrangement is observed on TEM images, but in this case, a hand-drafted line drawing of clay-particle long axes suggests that one particle orientation is better represented than others (Fig. 2D, E). This partial preferred orientation is subperpendicular to the vertical axis of cores, and may correspond to a compaction feature parallel to bedding. On the other hand, our observations give no evidence of bulk tectonic strain outside the deformation bands. Secondary mode SEM images show that the partial preferred orientation is more intense in lithologic Unit III (Fig. 2C). The preferentially oriented particles tend to form continuous bands corresponding to the layering observed in optical microscopy. 

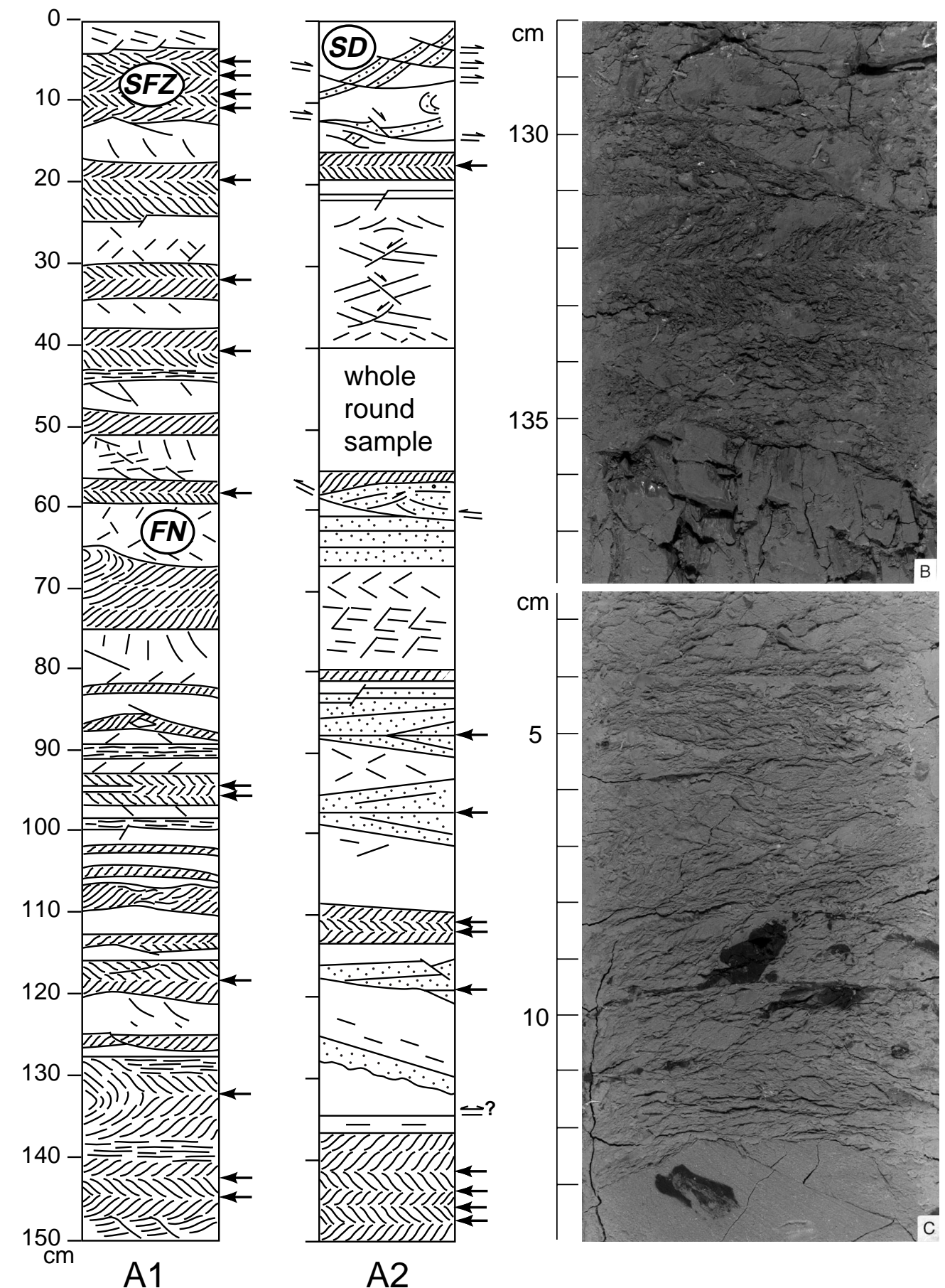

Figure 1. Macroscopic characteristics of scaly fabrics. A. Sketch of core faces showing the heterogeneous distribution of scaly fabrics in the décollement zone at Hole 948C. A1: Section 156-948C-11X-2, in lithologic Unit II; A2: Section 156-948C-12X-3, in lithologic Unit III. White = claystone; dots = siltstone layers; SFZ = scaly-fabric zone; FN = fracture network; SD = stratal disruption; thin arrows = microfaults; thick arrows = drilling-induced deformation ("biscuit" boundaries where "biscuits" rotated relative to each other). B. Macroscopic appearance of scaly fabrics in a zone with inclined boundaries (Sample 156-949B$13 X-2,128-138 \mathrm{~cm}$; lithologic Unit II, from a thrust-fault zone in the lower part of the accretionary prism). Fracture networks occur outside the scaly-fabric zone. Changes of dip direction of the scaly fabric occur along sub-horizontal drilling-induced "biscuit" boundaries. C. Macroscopic appearance of scaly fabrics in a zone with sub-horizontal boundaries (Sample 156-948C-11X-2, 2.5-14 cm; lithologic Unit II, décollement). Fracture networks and undeformed sediment occur outside the scaly-fabric zone at the top and bottom of picture, respectively; black spots are manganese oxide. 

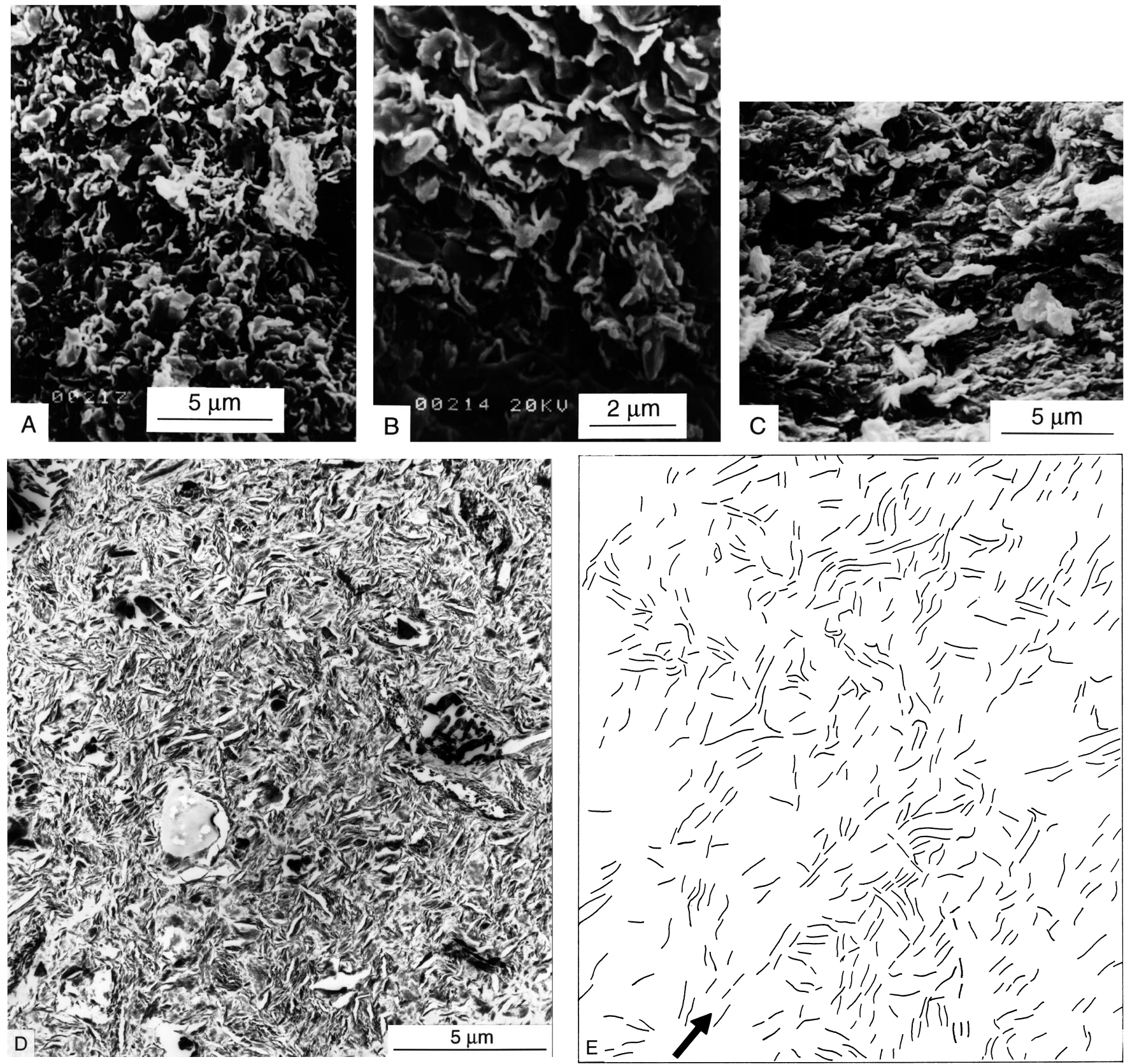

Figure 2. Clay-particle arrangement in macroscopically undeformed claystone. A. Secondary SEM image showing the highly porous random arrangement of clay particles in claystone from lithologic Unit II (Sample 156-948C-5X-3, 72-74 cm). B. Same sample as A, with higher magnification. C. Secondary SEM image showing sub-horizontal partial preferred orientation of clay particles due to compaction in claystone from lithologic Unit III (Sample 156-948C-14X-1, 99-101 cm). D. TEM image showing the clay-particle arrangement in claystone from lithologic Unit II (Sample 156-949B-22X-1, 113-116 cm). E. Line-drawing of (D). Arrow: partial preferred orientation of clay-particle long axes, possibly a weak compaction feature, parallel to bedding.

\section{S-C Bands}

These bands are named from their geometrical analogy with the S-C tectonites described in ductile metamorphic rocks (Berthé et al., 1979; Lister and Snoke, 1984). The S-C tectonites correspond to sheared domains in which S-surfaces (S for "schistosity") oblique to the shear zone are related to the accumulation of finite strain, whereas C-surfaces (C for "cisaillement," [shear in French]) subparallel to the shear zone correspond to displacement discontinuities or zones of high shear strain. As we show below, the geometrical analogy in- ferred here is observable at all microscopic scales, but only the high magnification secondary mode SEM images give sufficient resolution to observe details of the clay-particle arrangement, attesting to the validity of the analogy in a genetic sense.

\section{Optical Microscopy}

At this scale, the S-C bands usually correspond to bands up to a few millimeters thick, subparallel to, or dipping at low angle relative to, the boundaries of the macroscopic scaly-fabric zone. These bands 

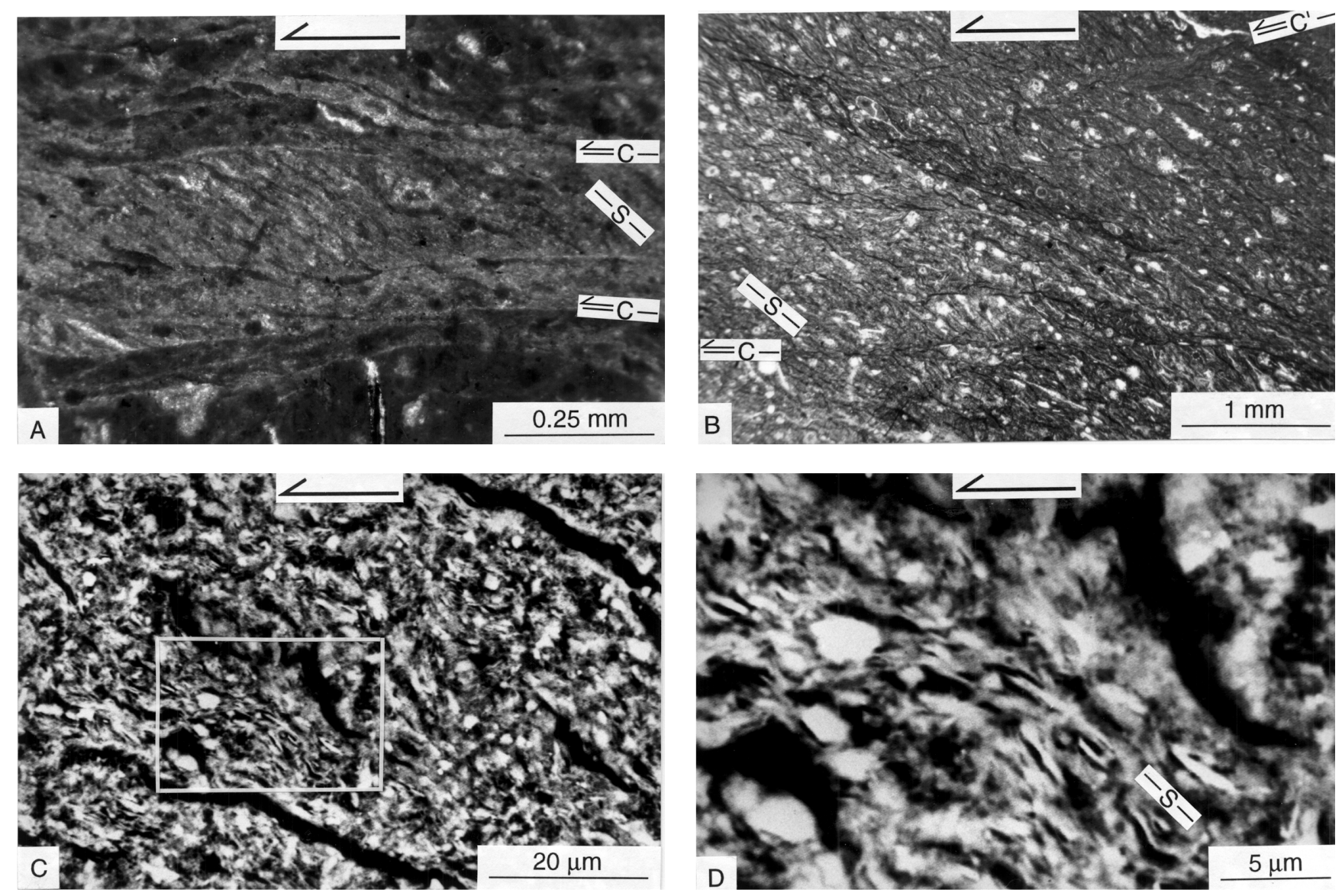

Figure 3. Microscopic appearance of S-C bands. Arrow at top of photos = bulk shear; $\mathrm{C}=$ shear surfaces sub-parallel to bulk shear; $\mathrm{C}^{\prime}=$ shear surfaces extensional relative to bulk shear; $\mathrm{S}=$ foliation. A. Micrograph of a submillimeter-thick S-C band (Sample 156-948C-11X-2, 68-72 cm). B. Micrograph of a centimeter-thick S-C band (Sample 156-948C-10X-5, 4-7 cm). C. Backscattered mode SEM image of S-foliation showing partial preferred orientation of clay particles; black bands are open fractures parallel to the foliation and resulting from sample air-drying (detail of the S-C band shown in B). Frame: location of (D). D. Detail of (C). A domain of undeformed clay occurs at upper right. E. Secondary mode SEM image of a S-C band (Sample 156-948C-2X-5, 83-87 cm). Undeformed clay occurs at top and left. Frame: location of (F). F. Detail of (E). The S-foliation is deflected along the sub-horizontal C-surfaces, and shows varying intensity of clay-particle preferred orientation and associated pore collapse. G. Secondary mode SEM image of a S-C band, with marked preferred orientation of clay particles and pore collapse along $\mathrm{C}$-surfaces, and varying intensity of clay-particle preferred orientation and associated pore collapse in the Sfoliation (Sample 156-948C-2X-5, 83-87 cm). Frame: location of (H). H. Detail of (G) showing lateral transition from a C-surface to the S-foliation. I. Original highly porous random arrangement of clay particles in undeformed domain a few tens of microns from the S-C band shown in (E).

are characterized by sharp boundaries (C-surfaces), and an oblique pervasive foliation (S-foliation) expressed by stripes of varying color of the claystone, paler than the undeformed claystone (Fig. 3A). The $\mathrm{S}$-foliation is sigmoidal, inclined to the C-surfaces and deflected along the latter. Secondary surfaces parallel or oblique at a low angle to the zone boundaries, and also deflecting the $\mathrm{S}$-foliation, may occur within the zone. Those secondary surfaces oblique to the zone boundaries dip in the opposite sense to the S-foliation, and are geometrically analogous to the $\mathrm{C}^{\prime}$ surfaces defined by Ponce de Leon and Choukroune (1980) in metamorphic shear zones.

In rare cases, an S-foliation deflected along minor $\mathrm{C} / \mathrm{C}^{\prime}$ surfaces is developed at the centimeter scale and corresponds to the microstructure of a whole macroscopic scaly-fabric zone (Fig. 3B).

\section{Backscattered Mode SEM}

On low magnification $(<1000)$ images, clay particles are not visible and the S-foliation corresponds to open fractures. High magnification images show that the open fractures are parallel to a marked preferred orientation of clay-particle long axes (Fig. 3C,D). Howev- er, distribution of strain is heterogeneous, and domains with preferred clay-particle orientation coexist with adjacent domains where the original arrangement is preserved (Fig. 3D).

\section{Secondary Mode SEM}

On these images (Fig. 3E through $\mathrm{H}$ ), the $\mathrm{C} / \mathrm{C}^{\prime}$-surfaces correspond to narrow $(\leq 10 \mu \mathrm{m})$ bands paralleled by a strong preferred orientation of clay-particle long axes. The preferentially oriented particles are tightly packed, with pore size strongly reduced in relation to the undeformed claystone (Fig. 3I), and pores showing a high length/ width ratio $(\mathrm{L} \leq 5 \mu \mathrm{m} ; \mathrm{w} \leq 1 \mu \mathrm{m})$. Between the $\mathrm{C} / \mathrm{C}^{\prime}$-surfaces, the $\mathrm{S}$ foliation corresponds to preferentially oriented clay particles with their long axis oblique to the $\mathrm{C} / \mathrm{C}^{\prime}$-surfaces and deflected along the latter. Preferred clay-particle orientation is more or less complete in the S-foliation domains. Pore size diminishes and length/width ratio of pores increases with increasing preferred clay-particle orientation.

The clay-particle arrangement observed on the secondary mode SEM images is best explained in terms of shear zones where the $\mathrm{C} / \mathrm{C}^{\prime}-$ surfaces correspond to shear surfaces, and the S-foliation to a flatten- 

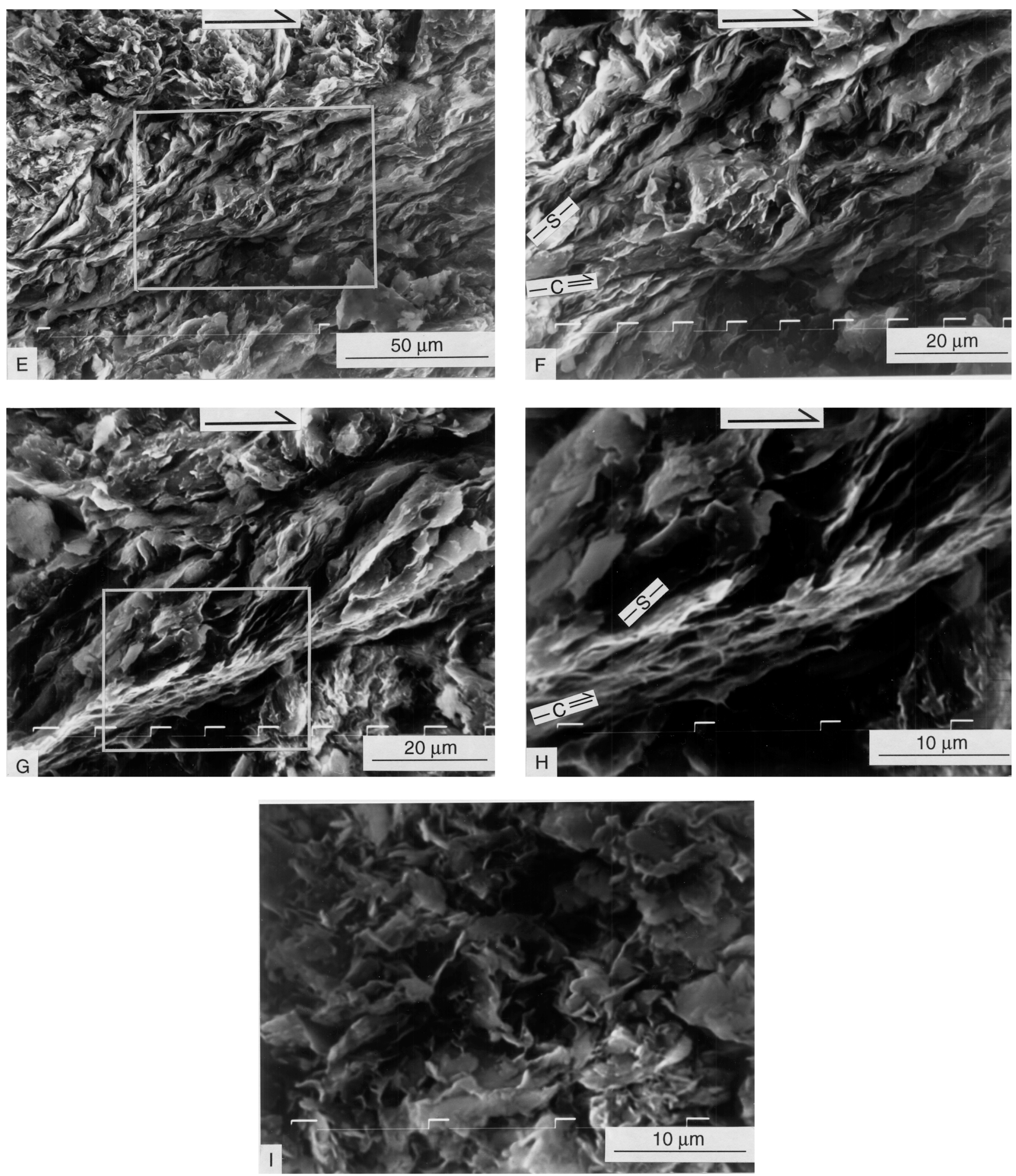

Figure 3 (continued).

ing fabric developed between the shear surfaces. The different degrees of S-foliation intensity show that the S-foliation develops by progressive rotation of clay particles and resulting porosity collapse. The angular relationships between the $\mathrm{C} / \mathrm{C}^{\prime}$-surfaces and the S-foliation indicate the sense of shear, the sense of movement of the hanging wall being opposite to the dip direction of the S-foliation. The C-surfaces are parallel to the bulk shear direction, whereas the $\mathrm{C}^{\prime}$ surfaces correspond to extensional substructures with respect to this direction. Although the deformation mechanisms are different, there is thus an effective analogy between the microstructures described here and the S-C tectonites in metamorphic rocks. The geometrical asymmetry can be used in the same way as a shear-sense indicator. 

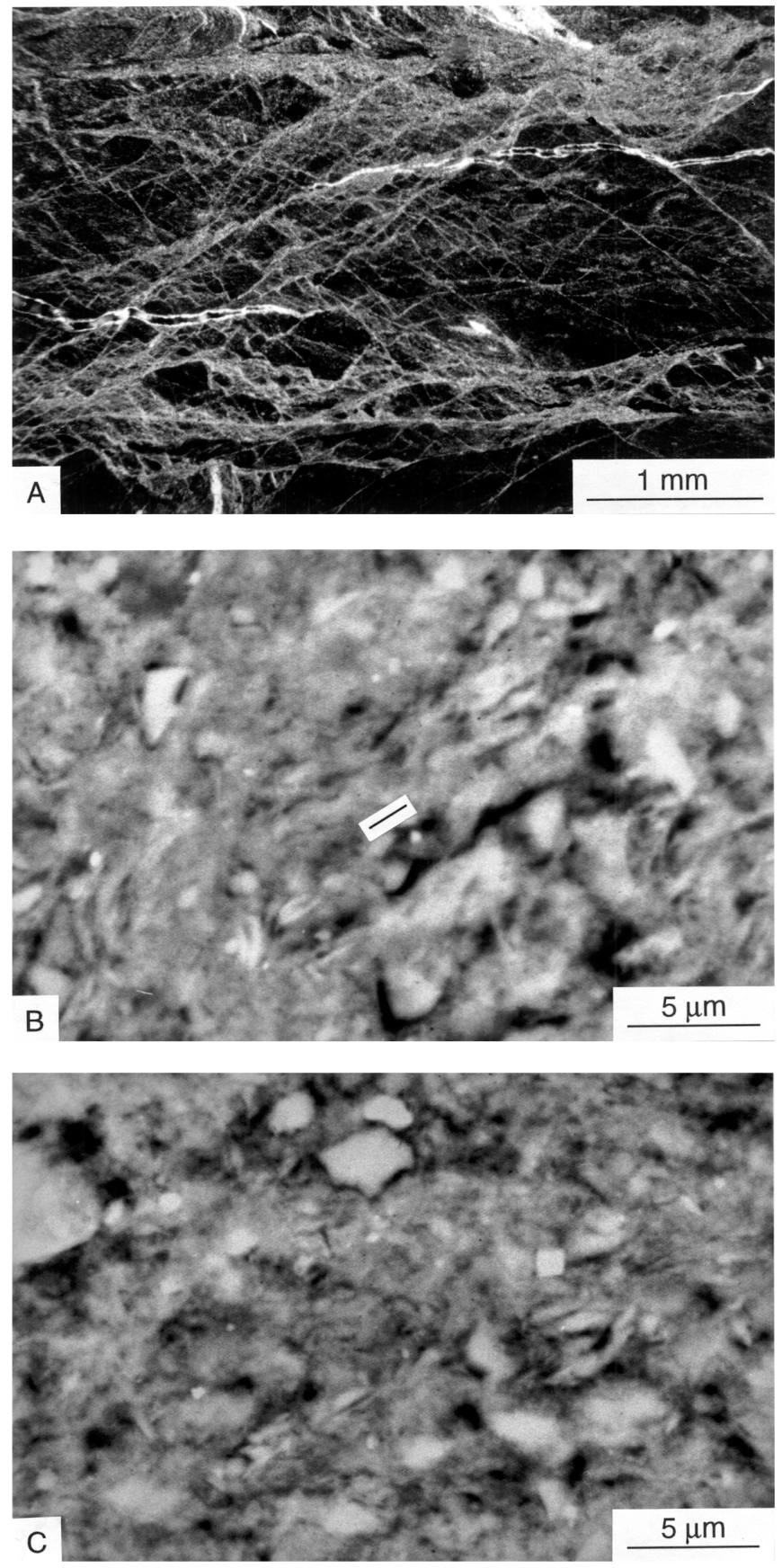

Figure 4. Microscopic appearance of fracture networks. A. Micrograph of fracture network with cross-cutting deformation bands (Sample 156-948C19X-7, 23-27 cm). B. Backscattered SEM image in a deformation band, showing left-dipping partial preferred orientation of clay particles (bar), subparallel to the band (Sample 156-948C-10X-5, 4-7 cm). C. Backscattered SEM image in undeformed claystone a few tens of microns away from the deformation band shown in (B).

\section{Fracture Networks}

\section{Optical Microscopy}

The fracture networks are formed by "fractures" with variable dip-direction and showing cross-cutting rather than anastomosing relationships (Fig. 4). The "fractures" correspond to sharp surfaces, or to deformation bands up to a few tens of microns thick that are lighter in color than the undeformed claystone (Fig. 4A). An open fracture may or may not occur along these bands. This aspect is similar to that of the shear surfaces responsible for the offset of bedding in stratal disruption. Where no bedding is visible, possible shear movement along the fractures is indicated by millimetric offset, in general extensional, of earlier fractures by later ones.

\section{Backscattered Mode SEM}

On low magnification $(<1000)$ images, clay particles are not visible and only the open fractures are observed. High magnification images show partial preferred orientation of clay-particle long axes in the macroscopic deformation bands (Fig. 4B, C).

\section{Optical Microscopy}

\section{Spaced Foliation}

At this scale, the spaced foliation is defined by folia dipping in a single direction, at moderate to high angles relative to the boundaries of the macroscopic scaly-fabric zone (Fig. 5A through E). The folia show variable width and spacing. In weakly deformed domains, the folia correspond to sharp surfaces, commonly open fractures, in undeformed sediment (Fig. 5A). These surfaces are spaced a few tenths of millimeters apart and are relatively straight and sub-parallel to each other, with a few anastomosing branches. When grading into more intensely deformed domains, the folia become more closely spaced and form a complex anastomosing pattern (Fig. 5B, C), up to being coalescent and undulose in the most intensely deformed domains (Fig. 5D, E). In those domains with intense foliation, the folia correspond to sharp surfaces, or to deformation bands up to a few tens of microns thick that are lighter in color than the undeformed claystone.

\section{Electronic Microscopy}

The most detailed images have been obtained with the secondary mode SEM (Fig. 5F through K). They show that the sharp surfaces observed with the optical microscope in the weakly deformed domains correspond to narrow $(<15 \mu \mathrm{m})$ deformation bands featuring (1) strong preferred orientation of clay-particle long axes parallel to the bands, and (2) tight packing of the preferentially oriented clay particles without visible pores (Fig. 5F, G). Boundaries of the deformation bands are sharp, and claystone outside the bands shows the highly porous arrangement with randomly oriented clay particles typical of undeformed sediment. No deflection of clay particles is observed at the level of the band boundaries.

Where the spaced foliation forms a denser, anastomosing network (Fig. 5H, left side), the aspect of the folia is similar to that described above, but in this case partial preferred orientation of clay-particle long axes associated with porosity collapse also occurs in the lenses bounded by the folia (Fig. 5I). These preferentially oriented particles (bar in Fig. 5I) are oblique to, and deflected along, the folia, indicating that the latter acted as shear zones (small arrows in Fig. 5I). Shear movement of the hanging wall is in a sense opposite to the dip direction of the foliation, i.e., contractional.

The thickest folia correspond to domains up to $1 \mathrm{~mm}$ thick (Fig. $5 \mathrm{H}$, right side), with penetrative preferred orientation of clay-particle long axes sub-parallel to the folia, and marked pore collapse (Fig. 5J, $\mathrm{K})$. In these domains, the preferentially oriented particles are deflected by shear surfaces oblique to the folia (small arrows in Fig. 5H), resulting in a geometry similar to that of the S-C bands. At smaller scale, local second-order S-C geometries show that the foliation also acted as shear surfaces (small arrows in Fig. 5J), with the sigmoidal geometry indicating the same sense of shear movement as in the adjacent domains of anastomosing folia (Fig. 5I).

Increasing density and thickness of the folia correspond to increasing strain. Clay-particle arrangement in the domains with largest 
strain is similar to that of the S-C bands (Fig. $5 \mathrm{H}$, right side). On the other hand, kinematic interpretation of deformation bands in the domains with weakest strain (Fig. 5F) is made difficult by the absence of deflected clay particles at band boundaries (Fig. 5G). Because clay particles are not deflected, the folia in those domains of weak deformation may correspond to flattening bands rather than shear bands. The fact that these bands dip subparallel to the folia showing a millimeter-scale S-C geometry in the same sample (Fig. 5H, right part), supports this interpretation. Therefore, we infer that the $\mathrm{S}-\mathrm{C}$ geometry apparent in the right side of Figure $5 \mathrm{H}$ represents the final stage of evolution of initially spaced flattening bands (Fig. 5F), the left side of Figure $5 \mathrm{H}$ illustrating an intermediate stage. Increasing intensity of bulk shear is likely to have activated the flattening bands as second-order shear zones (Fig. 5I, J).

\section{Microstructure Associations}

In many samples, the three microstructures show a typical mode of spatial association, as illustrated by the examples shown in Figure 6 and summarized in Figure 7:

1. Fracture networks (FN in Figs. 6 and 7) occur at the periphery of the S-C bands (S-C in Figs. 6A and 7), forming, together with the latter, deformation zones a few millimeters thick. In some cases (Fig. 6B), a similar relationship is observed between fractures networks and millimeter-thick, sharply bounded domains with closely-spaced foliation (SF in Fig. 6B). The latter domains may correspond to incipient $\mathrm{S}-\mathrm{C}$ bands in which increasingly closer-spaced foliation evolves to an S-foliation, as discussed in the previous section.

2. Spaced foliation (SF in Fig. 6A and 7) occurs in the intervals between the deformation zones formed by the $\mathrm{S}-\mathrm{C}$ bands and adjacent fracture networks. The spaced foliation dips in the same direction as the S-foliation in the S-C bands, that is, opposite to the sense of displacement of the $\mathrm{S}-\mathrm{C}$ band hanging wall, with a moderate to high angle with respect to the S-C band.

Relationships between the microstructures show that the spaced foliation is involved in the formation of both the fracture networks and the S-C bands:

1. Fracture networks are formed by the interference of fractures of opposite dip direction. One of the two families corresponds to the spaced foliation, whereas the other family is present only at the periphery of the S-C bands, with low to moderate dip with respect to the $\mathrm{S}-\mathrm{C}$ band (Fig. 6A, B, E). Fractures of each group can offset both those of the other group and the $\mathrm{S}-\mathrm{C}$ band boundaries. Offsets are extensional with respect to the trend of the S-C band (Fig. 6A, E). Fractures corresponding to the spaced foliation are antithetic to the $\mathrm{S}-\mathrm{C}$ bands, equivalent to the $\mathrm{X}$ shears in the Riedel terminology (e.g. Bartlett et al., 1981), whereas the fractures of the other family are synthetic to the S-C bands, equivalent to the R shears in the Riedel terminology (or the $\mathrm{C}^{\prime}$ surfaces, in the S-C terminology; Ponce de Leon and Choukroune, 1980). Most often, the X shears were the last that were active (Fig. 6E).

2. As suggested above, increasing strain may result in the evolution of the spaced foliation to S-C bands. The folia can also be activated as millimeter-scale thrusts, the zone then acting as a micro-contractional duplex (Fig. 6D).

Therefore, the spaced foliation is the fundamental microstructural element in the scaly fabric zones, either as an independent microstructure or through its influence on the formation of the other two features. This aspect is discussed further below in a kinematic model of scaly-fabric formation.

\section{Relationships with the Macroscopic Structures}

In many scaly-fabric zones observed on core faces, the scaly fabric defines a foliation oblique to the zone boundaries (Fig. 1). This inclined foliation is the macroscopic expression of the dominance of the spaced foliation in the scaly-fabric microstructures (Fig. 7). In favorable cases, it is possible to identify on core faces the different types of microstructures. The dip-direction of the foliation with respect to the boundaries of the scaly-fabric zone can thus be used as a shear sense indicator; in other words, it is opposite to the sense of displacement of the hanging wall.

Comparison of macro- and microstructures shows that deformation is heterogeneous at all scales. At the macroscopic scale, shear strain is mainly concentrated in centimeter-thick scaly-fabric zones, whereas at the microscopic scale it is mainly concentrated in millimeter-thick S-C bands. At both scales, these zones of high strain are separated by intervals of weakly deformed sediment: the fracture networks or stratal disruption defined at the macroscopic scale, and the fracture networks and spaced foliation defined at the microscopic scale. Although the kinematics of the macroscopic fracture networks are difficult to unravel, it is probable that fractures observed at the macro- and microscale have similar origin.

A consequence of deformation heterogeneity is that only a very small portion of sediment is actually affected by clay-particle reorientation in fault zones. As detailed in a previous section, the macroscopic scaly-fabric zones constitute only about $8.8 \%$ of the décollement thickness in Hole 948C, implying that the proportion of sediment actually affected by clay-particle reorientation probably does not exceed $1 \%$ or $2 \%$ of the décollement thickness. This explains why clay-particle preferred orientation in the décollement was not detected by bulk measurements such as the anisotropy of magnetic susceptibility (Housen et al., 1996) and the polarization of acoustic shear waves (Peacock et al., Chapter 21, this volume).

\section{Summary of Sediment Behavior and Deformation Mechanisms}

As it is emphasized above, the deformation of the Barbados prism sediments is characterized by the concentration of strain in discrete deformation zones of different scales: the micrometer- to millimeterthick deformation bands making the scaly fabrics; the centimeterthick scaly-fabric zones, fracture networks and stratal disruption in fault zones; and the meter- to decameters-thick fault zones in the prism, including the basal décollement. Such a distribution of deformation indicates that the prim is overall behaving as a brittle structure (Maltman et al., Chapter 22, this volume). However, at the clay particle scale, the fundamental deformation mechanism in all the types of micrometer- to millimeter-thick deformation bands making the scaly fabrics is the rotation of clay particles, with associated porosity collapse, leading to formation of domains with preferred orientation of clay particles and low porosity. Therefore, at this scale, deformation corresponds to compactional plastic strain. Clay-particle rotation involves both particle boundary sliding and some amount of particle deformation (bending), and thus corresponds to controlled particulate flow in the sense of Borradaile (1981). Particulate flow corresponds to ductile flow at the scale of the aggregate, and it is typical of poorly lithified sediment (Knipe, 1986, 1989). The excellent resolution of TEM images illustrates spectacularly the preferred orientation of clay particles in the scaly-fabric zones (Fig. 8), but the mode of sampling for TEM observation makes it difficult to establish the relationships between the micrometer-scale TEM observations and the different types of microstructures described above. 


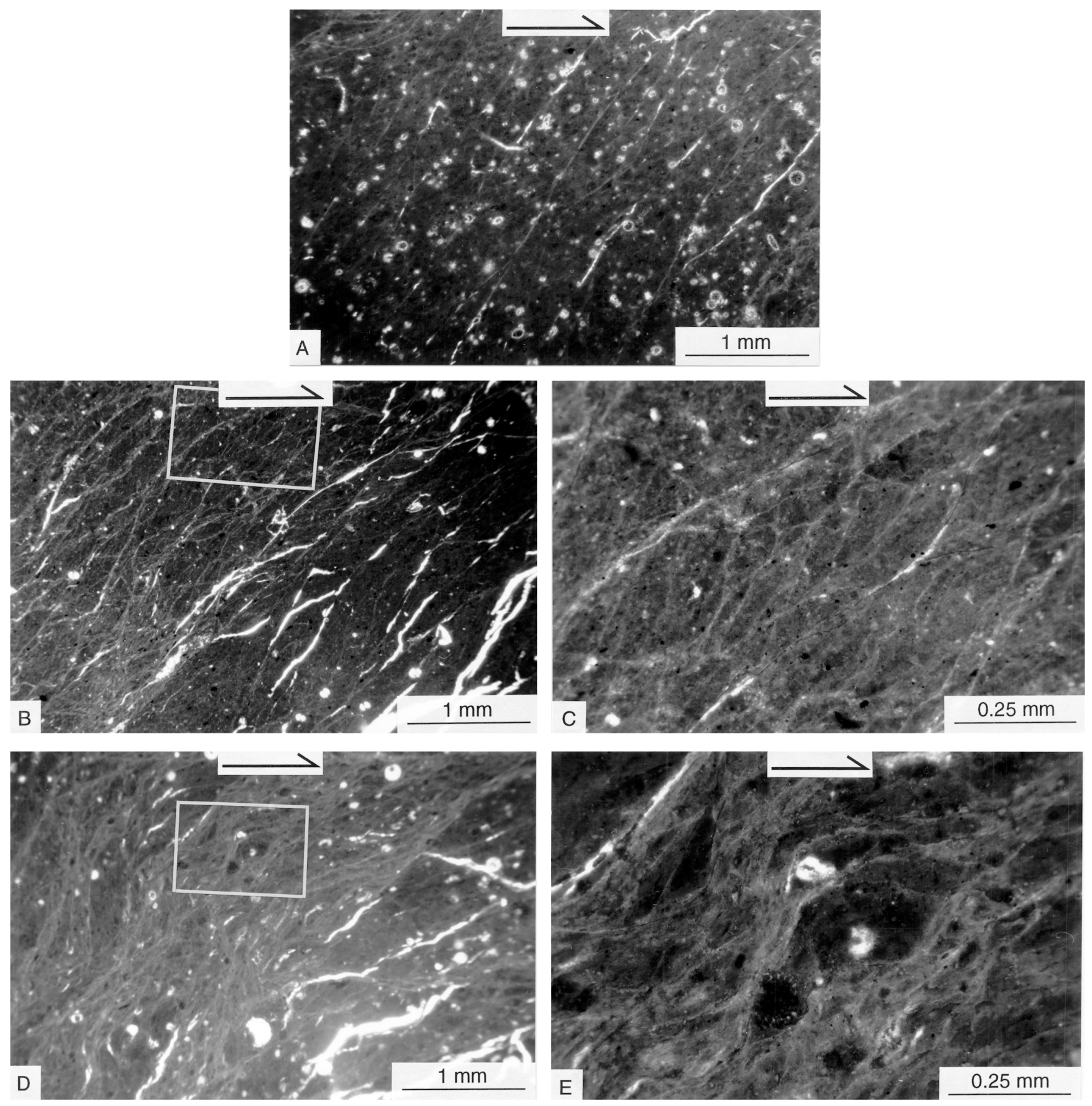

Figure 5. Microscopic appearance of spaced foliation. Arrow at top of photos = bulk shear. A. Micrograph of weak spaced foliation, with sharp and relatively straight folia (Sample 156-948C-11X-2, 57-61 cm). B. Micrograph of weak spaced foliation (right) passing laterally leftward to a denser, anastomosing pattern (Sample 156-948C-2X-5, 78-81 cm). Frame: location of (C). C. Detail of (B) in domain of dense foliation. D. Micrograph of very dense and undulose spaced foliation (Sample 156-948C-11X-2, 68-72 cm). Frame: location of (E). E. Detail of (D). F. Secondary mode SEM image of weak spaced foliation; at this scale, only open fractures are visible (Sample 156-948C-2X-5, 101-103 cm). White rectangle: location of (G). G. Detail of (F) showing marked preferred orientation of clay particles and complete pore collapse in a few- $\mu \mathrm{m}$-thick deformation band. No deflection of clay particles is visible at band boundaries. A poorly developed deformation band occurs $30 \mu \mathrm{m}$ above the main band. Outside the bands, the highly porous random arrangement of clay particles typical of the undeformed claystone is preserved. H. Secondary mode SEM image of dense spaced foliation (left) passing laterally to very dense foliation (right). The foliation is deflected along sharp shear surfaces (small arrows; Sample 156-948C-2X-5, 101-103 cm). White rectangles: location of (I; left) and (J; right). The area shown in this picture is located a few millimeters above that shown in $(\mathrm{F})$, with the same picture orientation. I. Detail of (H, left part), showing partial preferred orientation of clay particles (bar) in the intervals between the steeply dipping deformation bands activated as shear surfaces (small arrows). J. Detail of (H, right part), showing pervasive preferred orientation of clay particles and marked pore collapse, with a small S-C band at upper center (small arrows). Frame: location of (K). K. Detail of (J). 

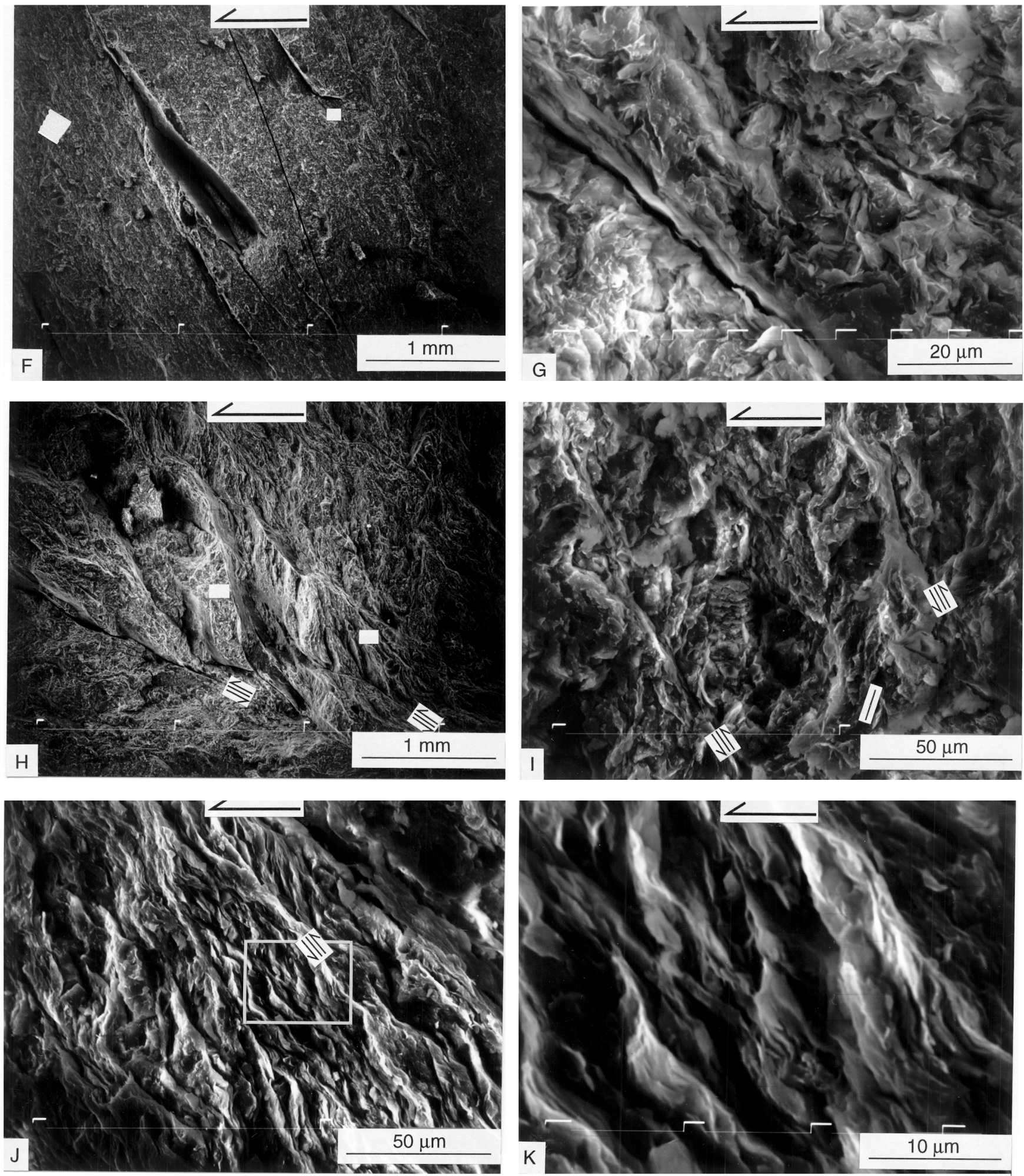

Figure 5 (continued)

\section{DISCUSSION}

The Problem of Drilling-Induced Deformation

A particular problem in this study has been the difficulty of distinguishing natural deformation structures from artifacts related to drilling. Rotary drilling in these poorly lithified sediments breaks the cores into "biscuits" a few centimeters to tens of centimeters long.
The truncation surfaces are subhorizontal, and biscuits rotate with respect to each other at the level of these surfaces (Fig. 1). A band of "drilling slurry" with a massive, homogeneous aspect is typically present at biscuit boundaries. A similar slurry also forms at core edges due to relative rotation between the core and the plastic liner. The drilling slurry is easily recognizable at the macroscopic scale, and was taken into account during on board sampling. 


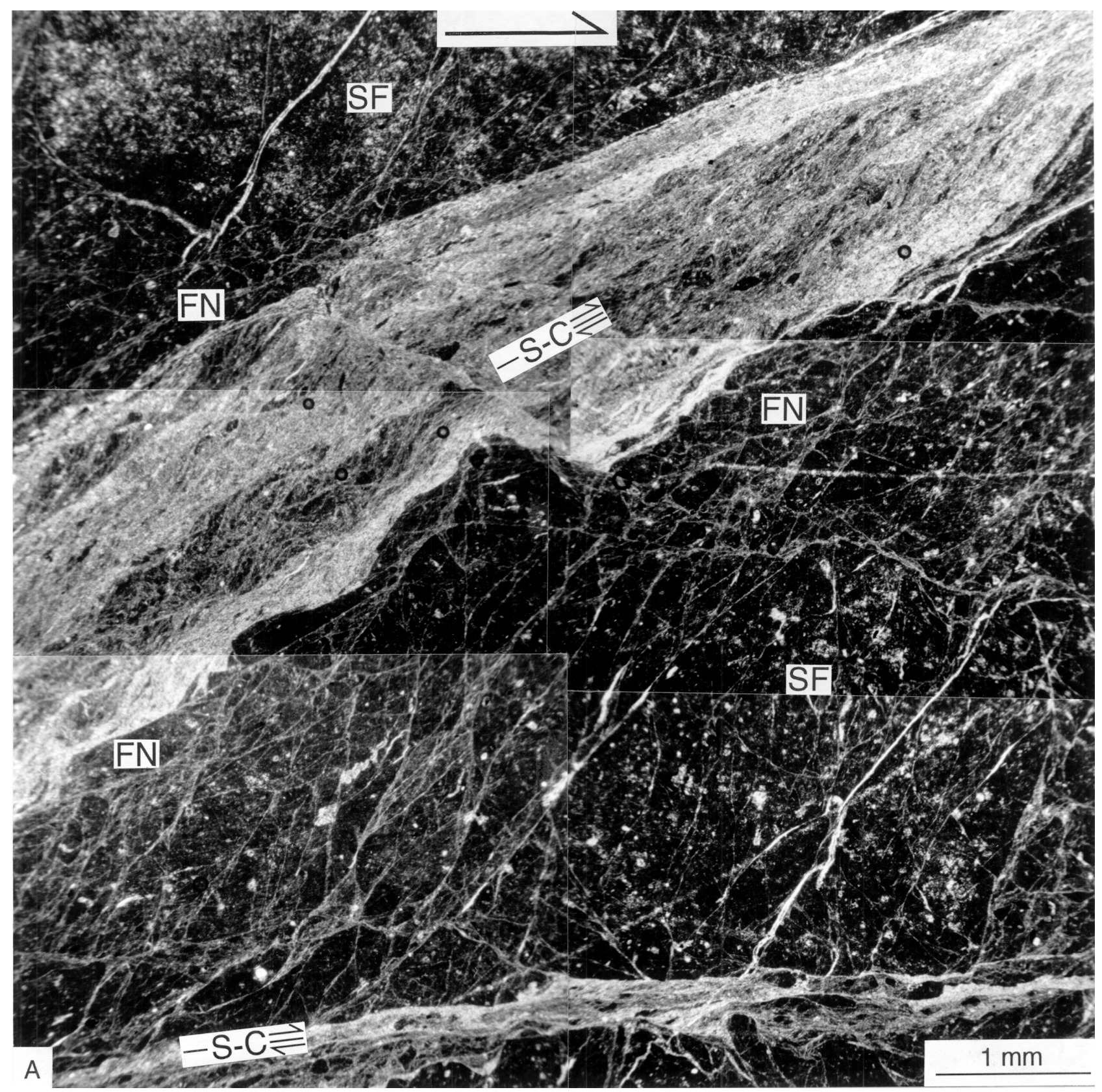

Figure 6. Mode of association of the microstructures forming the macroscopic scaly fabric (micrographs). Arrow at top of photos = bulk shear. A. The light band at top is a millimeter-thick S-C band with top-to-the-right movement. Submillimeter-thick domains of fracture networks (FN) with deformation bands of opposite dipping directions occur above and below the S-C band. Spaced foliation (SF) occurs away from the fracture networks, with weak development above the S-C zone, and relatively dense development with anastomosing patterns below. At bottom of image, there occurs a sub-horizontal $0.3-\mathrm{mm}$-thick S-C band with top to the right movement. The fracture networks are formed by the cross-cutting of the spaced foliation and shear surfaces synthetic with the S-C bands. Inclination of the spaced foliation, interpreted as flattening band arrays, indicates top-to-the-right shearing, compatible with movement along the S-C bands. The main S-C band is the upper boundary of an inclined, centimeter-thick scaly-fabric zone which acted as a thrust zone, according to the sense of movement indicated by the microstructures (Sample 156-948C-3X-4, 141-144 cm). B. Shear band with spaced foliation (SF), which density increases leftward (i.e., an incompletely developed S-C band), with adjacent fracture networks (FN; Sample 156-948C-14X-3, 103-107 cm). Frames: location of (C, center), (D, left), and (E, bottom). C. Detail of (B) showing dense spaced foliation. D. Detail of (B) showing thrust activation (small arrows) of the foliation, with formation of a hanging wall anticline. The shear band thus acted as a millimeter-scale contractional duplex. E. Detail of (B) showing fracture network and minor S-C zones. Fracture network is formed by spaced foliation activated as normal faults antithetic to the bulk shear $(\mathrm{X})$ and $\mathrm{R}$ shear surfaces associated with the S-C zones. 

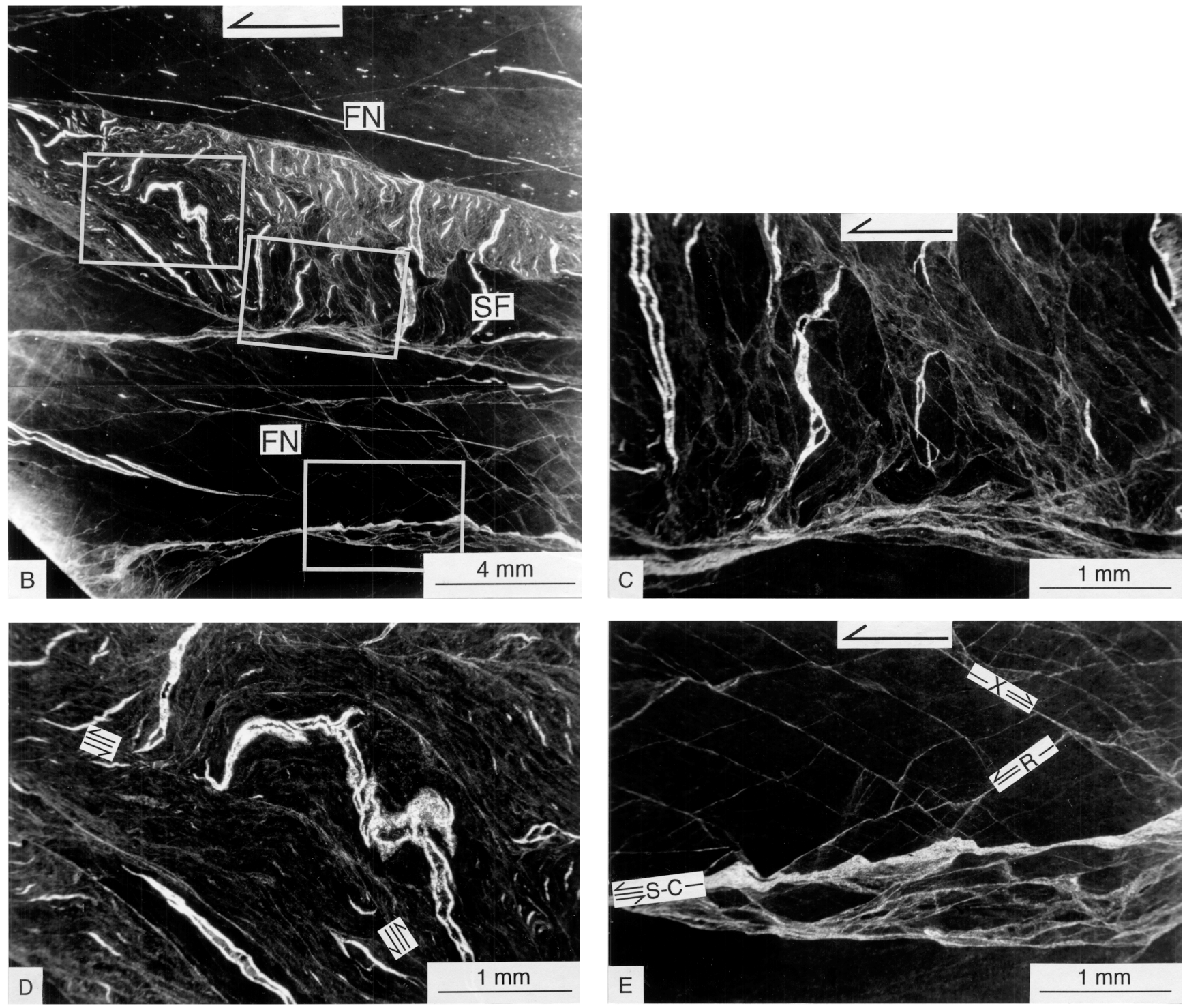

Figure 6 (continued).

However, the sensitivity of these unlithified clays to deformation makes it possible that some aspects of the deformation features recognized in samples and described above are also related to drilling disturbance. Indeed, biscuit rotation during drilling could have submitted the cores to a "ring-shear" effect, which would create artificial shear structures superimposed on the natural structures that are hardly distinguishable from the latter.

In some cases, the $\mathrm{S}-\mathrm{C}$ bands and adjacent fracture networks have a sub-horizontal trend and are located at the level of change of dip direction of the adjacent spaced foliation. It is thus probable that these particular S-C bands, and adjacent fracture networks, correspond to thin drilling-biscuit boundaries. In other cases, the density of fracture networks increases from the center toward the edge of the core, where they pass laterally into drilling slurry exhibiting preferred orientation of clay-particle long axes similar to the S-foliation and parallel to the core edge. Such lateral increase of deformation is also likely to be related to drilling disturbance.

On the other hand, a few S-C bands and adjacent fracture networks occur along boundaries of scaly-fabric zones that are inclined with respect to the vertical axis of the core (Fig. 6A) and, in some cases, have been truncated by sub-horizontal drilling-biscuit boundaries. In these cases, the $\mathrm{S}-\mathrm{C}$ bands and associated fracture networks are considered to be natural features. Similarly, the spaced foliation rotated by drilling biscuits is also considered to be natural in origin.

These examples show that both natural and drilling-induced deformation structures are present in the samples studied. They show similar microstructures, attesting to fundamentally similar deformation mechanisms. Based on the currently available data, it is thus virtually impossible to reach a definitive conclusion on the natural or artificial origin of many of the structures when considered individually. However, we believe that the microstructures described in this paper, and the kinematic model proposed for their formation, represent natural deformation features, and therefore give valuable information on the deformation processes in the décollement zone of the Barbados prism.

\section{Kinematic Model of Scaly Fabric Formation}

The mode of association of the three types of microstructures described above gives a basis for a kinematic model of scaly fabric formation (Fig. 9):

1. Microstructures begin to develop with the formation of spaced foliation consisting of narrow flattening bands oblique to bulk 


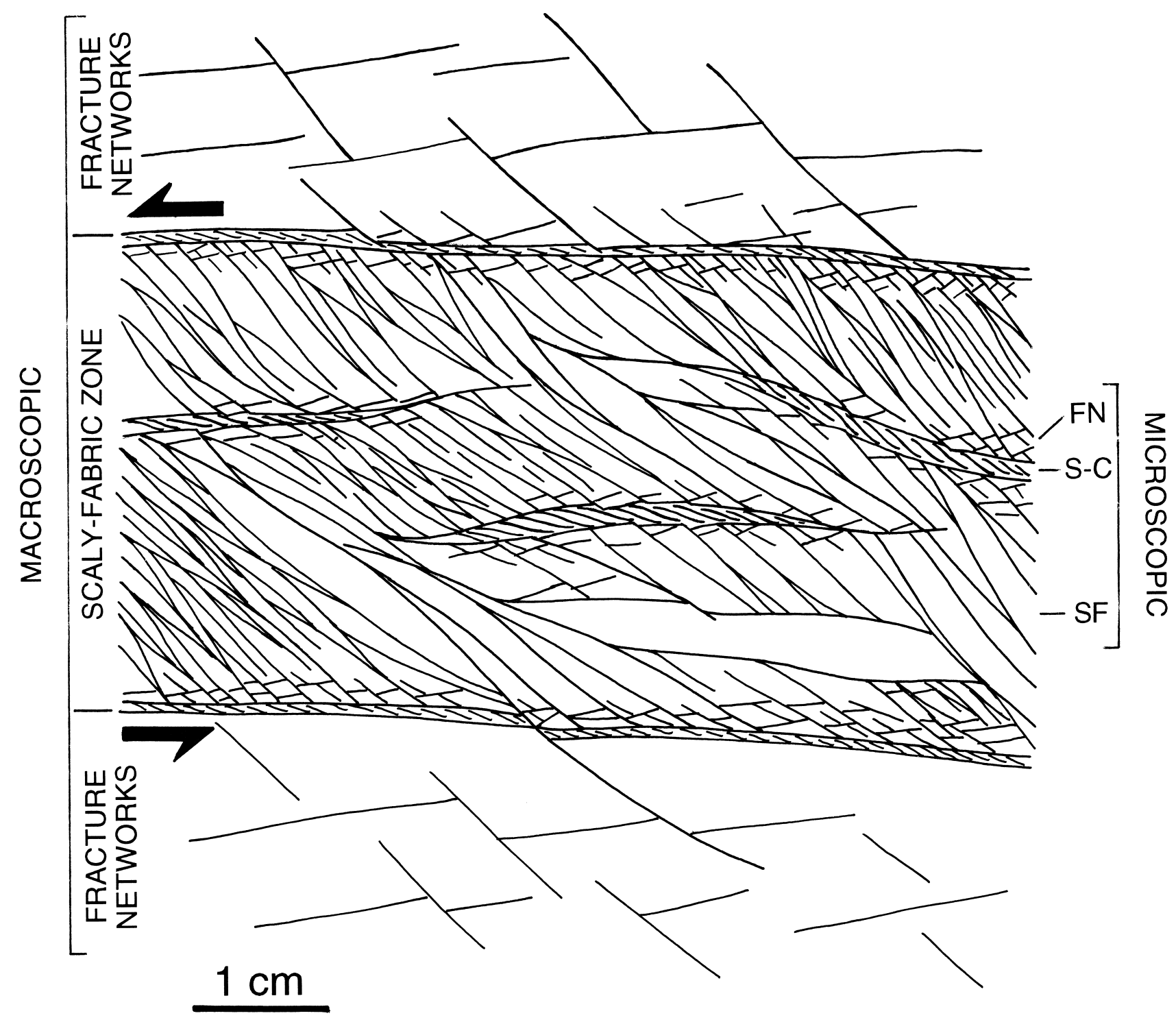

Figure 7. Summary sketch of microstructure associations forming the macroscopic scaly fabric. S-C = S-C band (millimeter-scale shear band); FN = fracture network; SF = spaced foliation.

shear (stage 1 in Fig. 9). Our observations give no evidence that bulk tectonic strain may have developed before strain localization occurs in the spaced foliation.

2. S-C bands are initiated by densification of the flattening band array in deformation zones parallel to bulk shear (stage 2 in Fig. 9). Increasing strain results (1) in a progression from discrete (spaced foliation) to pervasive (S-foliation) rotation of clay particles and porosity collapse, and (2) in a decoupling between the deformation zone and adjacent domains via the formation of the boundary C-surfaces (stage 3 in Fig. 9). The shear zone (SF) in Figure 6B corresponds to an intermediate stage between stages 2 and 3 in Figure 9. The folia can be activated as contractional shear surfaces, resulting in the formation of millimeterscale thrust-folds (Fig. 6B, C) or second-order S-C bands (Fig. $5 \mathrm{I}, \mathrm{J})$, with the zone then acting as a microcontractional duplex. We cannot exclude that synthetic $C$ and $C^{\prime}(R)$ shears may appear during stage 2 and its transition to stage 3 , resulting in a fracture network precursor of the $\mathrm{S}-\mathrm{C}$ band, but this hypothesis is not clearly supported by our observations (e.g., the absence of such synthetic shears in the incipient shear zone [SF] in Figure 6B).

3. Late partitioning of deformation results in the activation of discrete extensional shear surfaces (stage 4 in Fig. 9; Platt, 1984). These surfaces are (1) newly formed synthetic shears ( $C^{\prime}$, or $R$ shears), both inside and outside the S-C bands, and (2) folia of the spaced foliation outside the S-C bands, activated as antithetic shears (X shears). Those shear surfaces formed outside the $\mathrm{S}-\mathrm{C}$ bands constitute the fracture networks.

Densification of fracture networks at the periphery of a S-C band results in progressively thicker and more closely-spaced domains with clay-particle reorientation, which may eventually result in a pervasive $\mathrm{S}$-foliation (i.e., widening of the $\mathrm{S}-\mathrm{C}$ band).

This model implies that a macroscopic scaly-fabric zone has a tendency to evolve from a zone of discontinuous deformation with clay rotation localized in narrow (a few $\mu \mathrm{m}$ to $\mathrm{mm}$ ) discrete bands, to a 

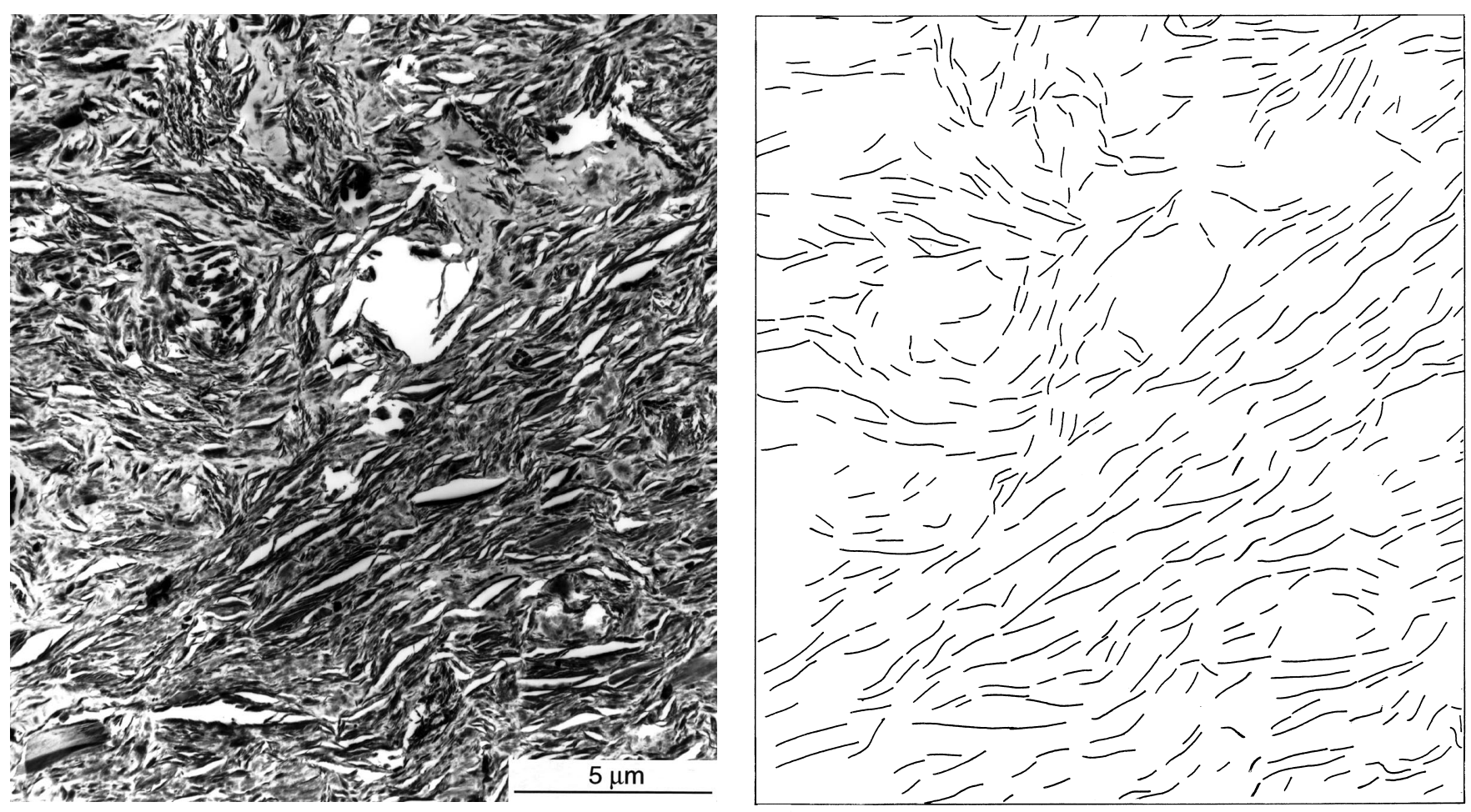

Figure 8. TEM image and line drawing of clay-particle arrangement in a scaly-fabric zone, with a domain of marked preferred orientation of clay particles (bottom right) adjacent to a domain where the original highly porous random arrangement of clay particles typical of the undeformed claystone is preserved (top left; Sample 156-949B-13X-03, 107-111 cm).

zone of S-foliation subpenetrative at the centimeter scale, as was observed in a few cases (Fig. 3B). However, as noted above, most of the scaly-fabric zones have not reached this stage; the general case corresponds to a highly heterogeneous distribution of strain, with only a small fraction of the sediment within the scaly-fabric zones being affected by clay-particle reorientation.

\section{Relationships between Scaly Fabrics and Porosity/Fluid Flow}

We have shown above that the deformation bands making the scaly fabrics are a result of compactional plastic shear strain. This mode of deformation is typical of normally consolidated to underconsolidated clayey sediments (Moore et al., 1986; Hicher et al., 1994). The assumption that the initial sediment was underconsolidated is supported (1) by the abnormally high porosities measured on samples of macroscopically undeformed sediment (Shipley, Ogawa, Blum, et al., 1995), and deduced from density data obtained by logging while drilling (Moore and ODP Leg 156 Shipboard Scientific Party, 1995); and (2) by the highly porous arrangement of randomly oriented clay particles preserved outside the deformation bands down to about 500 mbsf.

Porosity reduction in deformation bands necessarily results in expulsion of a significant amount of pore fluid, and pore distortion modifies the geometry of the pore network. Both processes imply close relationships between deformation and fluid behavior.

\section{Role of Fluids in the Formation of Scaly Fabrics}

Our microscopic observations and the kinematic model above are compatible with the interpretation that formation of the scaly fabrics is achieved through a localization-delocalization process controlled by close relationships between deformation and fluid behavior in incompletely consolidated sediment (e.g., Moore et al., 1986; Moore and Byrne, 1987):

1. The scaly fabric zones correspond to shear zones. Their formation is probably favored by a relatively high pore pressure/low effective stress (Hubbert and Rubey, 1959). In the case of the sites studied here, pore pressures in excess of hydrostatic pressure have been inferred from modeling of seismic reflection data (Shipley et al., 1994) and deduced from density data obtained by logging-while-drilling (Moore and ODP Leg 156 Shipboard Scientific Party, 1995).

2. Pore fluid expelled by compactional strain in deformation bands is drained along the bands. This assumption is supported by the mineralized veins, isolated barite crystals, and alteration colors in (or close to) some of the scaly-fabric zones, which attest to the preferential fluid circulation in these zones, and the low matrix permeability and chemical diffusivity of the claystone matrix.

3. Individual deformation bands lock as other bands created in adjacent undeformed sediment become more energetically efficient. This effect is presumably due to a combination of material strain-hardening, associated with an increasing number of face-to-face contacts of clay particles in the collapsed domains, and of system strain-hardening, associated with porepressure drop following fluid expulsion. This delocalization process may explain the heterogeneity of strain distribution in a great number of narrow deformation bands. The model applies at all scales. At the millimeter/centimeter scale, it applies to the formation of new deformation bands within or at the periphery of individual scaly-fabric zones, and it also applies at the meter scale to the formation of new scaly-fabric zones. 

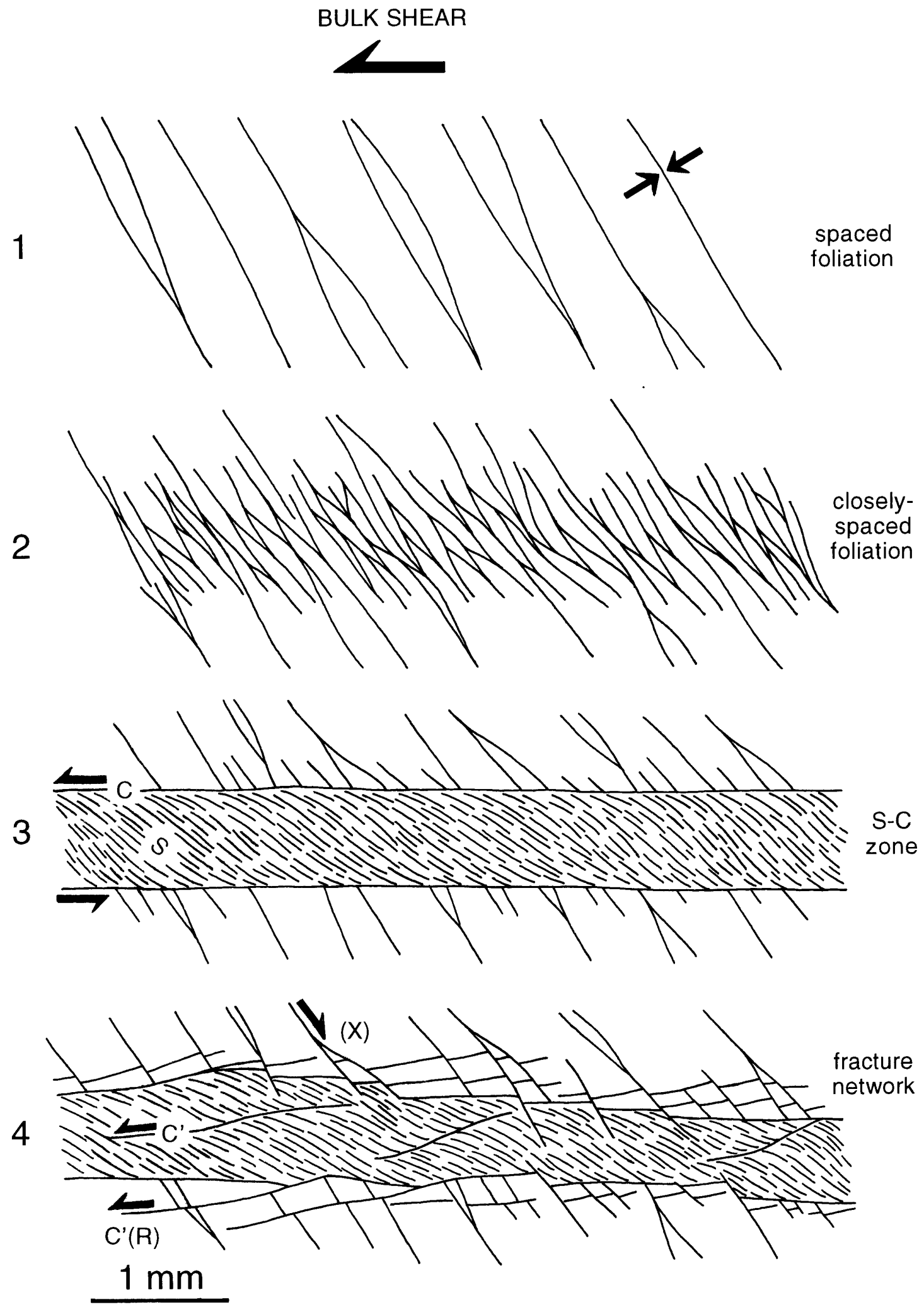

Figure 9. Kinematic model for the development of S-C bands (millimeter-scale shear bands; cf. Fig. 7) in the scaly-fabric zones. C (shear surfaces subparallel to bulk shear), $C^{\prime}$ (shear surfaces extensional relative to bulk shear), and S (foliation) refer to the terminology adopted for the S-C tectonites typical of the metamorphic shear zones (Berthé et al., 1979; Ponce de Leon and Choukroune, 1980), and (R) and (X) to the Riedel terminology (e.g., Bartlett et al., 1981). 
The process may imply progressive thickening of the deformed domains (Moore and Byrne, 1987), or, alternatively, a densification of the deformation bands (or scaly-fabric zones at a larger scale), new deformation bands (or scaly-fabric zones) being created in the intervals of undeformed sediment between the previously formed bands (or zones). In this case, the deformed domains would not thicken, but would be more intensely strained and might be thinned due to compaction associated with plastic strain. It seems that this densification model is applicable to the Barbados prism décollement, at least in its toe region (Maltman et al., Chapter 22, this volume)

\section{Scaly Fabric Zones as Fluid Drains}

There is an apparent contradiction between porosity collapse in deformation bands, which is likely to result in decrease of permeability, and the evidence that these bands acted as preferential pathways for fluids. This contradiction can be solved if the connected parting surfaces formed by the deformation bands are dilated by injection of high pressure pore-fluid (the "dynamic permeability" of Stephenson et al., 1994; Brown et al., 1994). Fluid circulation will also be facilitated by the low tortuosity resulting from preferred alignments of clay particles in these bands. We thus infer two possible types of relationships between fluid flow and strain in the scaly-fabric zones:

1. During formation of the scaly fabric, fluid circulating along the deformation bands is the fluid expelled from the local sediment by the compaction associated with the formation of these bands. The process is similar to squeezing a sponge, and although it can drive circulation of significant amounts of fluid, it will ultimately result in reduced permeability and fluid flow.

2. If overpressured fluid is injected from outside into a previously formed scaly-fabric zone, the connected deformation bands are likely to be dilated, allowing a transient episode of increased permeability. The injected fluid may be that being expelled by the formation of nearby scaly-fabric bands, or from deeper parts of the prism. The process is physically recorded in Leg 156 cores by the carbonate veins present in some scalyfabric zones, mainly along the spaced foliation. The veins are extensional veins-they did not form in association with the shear movement, and their direction of opening is parallel to the direction of the compression responsible for the foliation formation (Labaume et al., Chapter 5, this volume). Formation of veins thus results from a dilation event that occurs later than the compactional strain stage (Fig. 16 in Labaume et al., Chapter 5 , this volume). The meter-thick intervals with very high porosity revealed by density logging-while-drilling data in the décollement (Shipley, Ogawa, Blum, et al., 1995) may represent intervals dilated by the same process (the "hydrofractures" of Moore and ODP Leg 156 Shipboard Scientific Party, 1995). Geochemical data show that in the case of the carbonate veins, the circulating fluid originated from deeper and hotter parts of the prism (Labaume et al., Chapter 5, this volume), meaning that the dilated scaly-fabric zones are efficient pathways for long-distance fluid flow.

\section{Inferences on the Relationships Between Shear Strain and Displacement}

The discussion above implies that stages of significant shear stress (formation of scaly-fabric zones by compactional plastic shear strain) alternate with stages of relaxed shear stress (formation of extensional veins along dilated foliation). Relaxation of shear stress and dilation are probably related to episodes during which pore pressure is close to lithostatic pressure. If compactional strain is inhibited during these episodes, displacement along low-dipping fault zones is likely to be favored (Hubbert and Rubey, 1959). We thus infer that most of the displacement along the boundaries of the scaly-fabric zones may occur during periods of elevated pore pressure and may not be associated with compactional strain in the sediment, whereas the scaly fabrics would be formed during periods of lower (although still in excess of hydrostatic) pore pressure and would account for a limited displacement (see further discussion in Labaume et al., Chapter 5 , this volume). This interpretation is compatible with the fact that only a very low fraction of the sediment is affected by clay-particle reorientation in the fault zones, particularly in the décollement.

\section{Comparison with Previous Work}

Our observations contrast with the observations of Prior and Behrmann (1990a, 1990b) who studied equivalent material sampled during ODP Leg 110. These authors concluded that no preferred clay-particle orientation is associated with scaly fabrics from the décollement, and proposed that the scaly fabrics correspond only to the fractures resulting from unloading during core-recovery. The mode of microscopic observation of samples may partly explain this discrepancy. The studies by Prior and Behrmann (1990a, 1990b) utilized polished surfaces with backscattered mode SEM. In the present study, we have used three different techniques with sufficient magnification to observe particle and pore geometry: backscattered and secondary mode SEM, and TEM. Backscattered mode SEM gave the lowest resolution of the three techniques, which in the case of our samples is partially due to the difficulty of obtaining sufficiently polished observation surfaces in smectitic unlithified clay. In fact, secondary mode images have proved the most useful at the current stage of our work, because of (1) the zoom approach that allowed us to integrate observations from the centimetric to the micrometric scale, and (2) the 3-D vision of grain and pore geometry. The excellent resolution of TEM images also illustrates the preferred orientation of clay particles in zones of scaly fabric (Fig. 8).

However, our backscattered mode SEM images also show unambiguously the preferred orientation of clay particles in many samples (Figs. 3C,D, and 4B). The discrepancy with Prior and Behrmann (1990a, 1990b) is thus also because of the choice of representative samples. In fact, Prior and Behrmann (1990a, 1990b) did observe preferred clay-particle orientation in thrust $\mathrm{A}$, in the upper part of the prism (Hole 971B, $130 \mathrm{mbsf}$ ). Our study shows that deformation mechanisms are basically similar in the lower part of the prism and the décollement.

Our new observations are also compatible with other works on scaly fabrics of different origins, showing that preferred orientation of clay particles along the scaly surfaces is a general characteristic of scaly fabrics in clayey sediment (e.g., Moore et al., 1986; Lash, 1989).

Our work gives new insights on the kinematics of scaly fabric development. In their synthesis, Moore et al. (1986) assumed that all surfaces in the scaly fabrics are shear surfaces resulting from a protracted deformation history of shear zones. In such a case, no kinematic evolution may be recognized, and the resulting macroscopic foliation should be oriented subparallel to the boundaries of the scalyfabric zones. Our study shows that, in the case of the Barbados prism décollement, formation of the scaly fabrics involves both shear and flattening surfaces, with the latter being dominant during the initial stage of fabric formation and governing the trend of the macroscopic foliation which is often oblique to the scaly-fabric zone boundaries. The structures described in this paper present close geometrical and kinematical analogies with shear zones in ancient superficial nappes formed in similar conditions (Labaume et al., 1991).

\section{CONCLUSIONS}

Scaly fabrics in the décollement interval at the toe of the northern Barbados accretionary prism occur in $\mathrm{cm}$-thick zones interpreted as the shear zones where plastic shear strain and tectonic displacement 
are concentrated. Detailed microstructural investigation of the scaly fabrics shows that they are formed by a combination of three types of microstructures, each type comprising deformation bands a few microns to a few millimeters thick: (1) S-C bands are millimeter-thick shear bands named after their close geometrical analogy with the S-C tectonites commonly observed in metamorphic shear zones; (2) fracture networks comprise micrometer-thick shear bands of different dips with cross-cutting relationships; (3) A spaced foliation corresponds to arrays of $\mu \mathrm{m}$-thick flattening bands oblique to the bulk shear direction, possibly activated as contractional or extensional shear bands with increasing strain. In all microstructures, deformation is achieved by clay-particle rotation associated with pore collapse, resulting in the formation of domains with marked preferred orientation of clay particles. However, the sediment actually affected by this preferred orientation is usually a minor part of the scaly-fabric zones, and represents only a few percent of the total thickness of the décollement. This explains why preferred orientation of clay particles cannot be detected by bulk measurements such as the anisotropy of magnetic susceptibility and the polarization of acoustic shear waves.

The fracture networks typically occur at the periphery of the S-C zones, which represent zones of maximum strain. The spaced foliation occurs in the less strained domains. We propose a kinematic model in which the spaced foliation corresponds to the initial deformation feature, and densification of the spaced foliation arrays leads to the formation of the S-foliation in the S-C bands. The fracture networks form as a result of late strain partitioning on discrete extensional surfaces, and they may be precursors of the S-C band widening.

The deformation mechanism corresponds to the compactional plastic strain typical of normally consolidated or underconsolidated clayey sediments. Porosity reduction implies pore-fluid expulsion, and preferred clay-particle orientation along connected deformation bands creates potential pathways for drainage of fluids along the deformation zones. However, fluid circulation along compacted deformation bands requires dilation under excess pore-pressure conditions. We thus infer that cyclic variations of stress state, controlled by variations in pore pressure, occur in the scaly-fabric zones. Formation of scaly fabrics by compactional plastic shear strain is achieved during episodes of relatively low pore pressure and significant shear stress, and results in low permeability of deformation bands, whereas episodes of high pore pressure result in dilation, increased permeability, and inhibition of further compactional strain. Tectonic displacement along the sharp boundaries of the scaly deformation zones is likely to be favored during the high pore-pressure episodes, and the formation of scaly fabrics would account for only part of the cumulative displacement.

\section{ACKNOWLEDGMENTS}

We appreciate the care taken by the following, while dealing with these difficult materials: T. Ridgeway (University of Wales, Aberystwyth) with the thin-sections, J. Lapeyronie (INRA, Versailles) with the TEM samples, and L. Jenatton (Grenoble University) with impregnation of some of the samples. Staff of electronic microscopy services in Montpellier and Grenoble Universities helped with backscattered SEM observations, and B. Gélie (INRA, Versailles) with TEM observations. Our views on the relationships between strain and pore pressure benefited from discussions with P. Henry. This work was partly funded by CNRS-INSU (Paris), Programme Géosciences Marines, and the Natural Environment Research Council, UK. The manuscript was greatly improved by comments from B. Clennell, N. Lindsley-Griffin, and the ODP staff.

\section{REFERENCES}

Agar, S.M., Prior, D.J., and Behrmann, J.H., 1989. Back-scattered electron imagery of the tectonic fabrics of some fine-grained sediments: Implica- tions for fabric nomenclature and deformation processes. Geology, 17:901-904.

Bartlett, W.L., Friedman, M., and Logan, J.M., 1981. Experimental folding and faulting of rocks under confining pressure, Part IX. Wrench faults in limestone layers. Tectonophysics, 79:255-277.

Behrmann, J.H., Brown, K., Moore, J.C., Mascle, A., Taylor, E., and ODP Leg 110 Scientific Party, 1988. Evolution of structures and fabrics in the Barbados Accretionary Prism: Insights from Leg 110 of the Ocean Drilling Program. J. Struct. Geol., 10:577-591.

Berthé, D., Choukroune, P., and Jegouzo, P., 1979. Orthogneiss, mylonite and non-coaxial deformation of granites: the example of the South American Shear Zone. J. Struct. Geol., 1:31-42.

Borradaile G.J., 1981. Particulate flow of rock and the formation of cleavage. Tectonophysics, 72:305-321.

Brown, K.M., and Behrmann, J., 1990. Genesis and evolution of small-scale structures in the toe of the Barbados Ridge accretionary wedge. In Moore, J.C., Mascle, A., et al., Proc. ODP, Sci. Results, 110: College Station, TX (Ocean Drilling Program), 299-244.

Brown, K.M., Bekins, B., Clennell, B., Dewhurst, D., and Westbrook, G., 1994. Heterogeneous hydrofracture development and accretionary fault dynamics. Geology, 22:259-262.

Byrne, T., and Fisher, D., 1990. Evidence for a weak and overpressured décollement beneath sediment-dominated accretionary prisms. J. Geophys. Res., 95:9081-9097.

Cowan, D.S., 1985. Structural styles in Mesozoic and Cenozoic mélanges in the western Cordillera of North America. Geol. Soc. Am. Bull., 96:451462.

Cowan, D.S., Moore, J.C., Roeske, S.M., Lundberg, N., and Lucas, S.E., 1984. Structural features at the deformation front of the Barbados Ridge complex, Deep Sea Drilling Project Leg 78A. In Biju-Duval, B., Moore, J.C., et al., Init. Repts. DSDP, 78A: Washington (U.S. Govt. Printing Office), 535-548.

Hetzel, F., Tessier, D., Jaunet, A.M., and Doner, H., 1994. The microstructure of three $\mathrm{Na}^{+}$smectites: The importance of particle geometry on dehydration and rehydration. Clays Clay Miner., 42:242-248.

Hicher, P.Y., Wahyudi, H., and Tessier, D., 1994. Microstructural analysis of strain localisation in clay. Comput. Geotech., 16:205-222.

Housen, B.A., Tobin, H.J., Labaume, P., Leitch, E., Maltman, A.J., and ODP Leg 156 Shipboard Science Party, 1996. Strain decoupling across the décollement of the Barbados accretionary prism. Geology, 24:127-130.

Hubbert, M.K., and Rubey, W.W., 1959. Role of fluid pressure in the mechanics of overthrust faulting, I: Mechanics of fluid-filled porous solids and its application to overthrust faulting. Geol. Assoc. Am. Bull., 70:115-166.

Jeanbourquin, P., 1994. Early deformation of Ultrahelvetic mélanges in the Helvetic nappes (Western Swiss Alps). J. Struct. Geol., 16:1367-1383.

Knipe, R.J., 1986. Deformation mechanism path diagrams for sediments undergoing lithification. In Moore, J.C. (Ed.), Structural Fabric in Deep Sea Drilling Project Cores from Forearcs. Mem.-Geol. Soc. Am., 166:151-160.

1989. Deformation mechanisms - recognition from natural tectonites. J. Struct. Geol., 11:127-146.

Labaume, P., Berty, C., and Laurent, P., 1991. Syndiagenetic evolution of shear structures in superficial nappes: an example from the Northern Apennines, NW Italy. J. Struct. Geol., 13:385-398.

Lash, G.G., 1989. Documentation and significance of progressive microfabric changes in Middle Ordovician trench mudstones. Geol. Soc. Am. Bull., 101:1268-1279.

Lister, G.S., and Snoke, A.W., 1984. S-C mylonites. J. Struct. Geol., 6:617-638.

Lundberg, N., and Moore, J.C., 1986. Macroscopic structural features in Deep Sea Drilling Project cores from forearc regions. In Moore, J.C. (Ed), Structural Fabric in Deep Sea Drilling Project Cores from Forearcs. Mem.-Geol. Soc. Am., 166:13-44.

Maltman, A.J., Byrne, T., Karig, D.E., and Lallemant, S., 1993. Deformation at the toe of an active accretionary prism: synopsis of results from ODP Leg 131, Nankai, SW Japan. J. Struct. Geol., 15:949-964.

Moore, J.C., and Byrne, T., 1987. Thickening of fault zones: A mechanism of mélange formation in accreting sediments. Geology, 15:1040-1043.

Moore, J.C., Roeske, S.M., Lundberg, N., Schoonmaker J., Cowan, D.S., Gonzales E., and Lucas, S.E., 1986. Scaly fabrics from Deep Sea Drilling Project cores from forearcs. In Moore, J.C. (Ed.), Structural Fabric in Deep Sea Drilling Project Cores from Forearcs. Mem.-Geol. Soc. Am., 166:55-73. 
Moore, J.C., and the ODP Leg 156 Scientific Party, 1995. Abnormal fluid pressure and fault-zone dilation in the Barbados accretionary prism: Evidence from logging while drilling. Geology, 23:605-608.

Platt, J.P., 1984. Secondary cleavages in ductile shear zones. J. Struct. Geol., 6:439-442.

Ponce de Leon, M.I., and Choukroune, P., 1980. Shear zones in the Iberian Arc. J. Struct. Geol., 2:63-68.

Prior, D.J., and Behrmann, J.H., 1990a. Backscattered SEM imagery of finegrained sediments from Site 671, Leg 110-Preliminary results. In Moore, J.C., Mascle, A., et al., Proc. ODP, Sci. Results, 110: College Station, TX (Ocean Drilling Program), 245-255.

Prior, D.J., and Behrmann, J.H., 1990b. Thrust-related mudstone fabrics from the Barbados forearc: A backscattered scanning electron microscope study. J. Geophys. Res., 95:9055-9067.

Shipley, T.H., Moore, G.F., Bangs, N.L., Moore, J.C., and Stoffa, P.L., 1994. Seismically inferred dilatancy distribution, northern Barbados Ridge décollement: Implications for fluid migration and fault strength. Geology, 22:411-414.
Shipley, T.H., Ogawa, Y., Blum, P., et al., 1995. Proc. ODP, Init. Repts., 156: College Station, TX (Ocean Drilling Program).

Stephenson, E.L., Maltman, A.J., and Knipe, R.J., 1994. Fluid flow in actively deforming sediments: "dynamic permeability" in accretionary prisms. In Parnell, J. (Ed.), Geofluids: Origin, Migration, and Evolution of Fluids in Sedimentary Basins. Geol. Soc. London Spec. Publ., 78:113125.

Tessier, D., 1984. Etude expérimentale de l'organisation des matériaux argileux [Thèse d'Etat]. Paris VII Univ., Paris.

Waldron, J.W.F., Turner, D., and Stevens, K.M., 1988. Stratal disruption and development of mélange, Western Newfoundland: effects of high fluid pressure in accretionary terrain during ophiolite emplacement. J. Struct. Geol., 10:861-873.

Date of initial receipt: 1 February 1996

Date of acceptance: 15 August 1996

Ms 156SR-013 